OPEN ACCESS

Edited by: Roi Gazit,

Ben Gurion University of the Negev,

Israel

Reviewed by: Anandi Krishnan,

Stanford University, United States Arantzazu Alfranca, Hospital de la Princesa, Spain

*Correspondence: Stephen Tracy Oh stoh@wustl.edu

Specialty section: This article was submitted to Cytokines and Soluble Mediators in Immunity, a section of the journal

Frontiers in Immunology

Received: 20 March 2021 Accepted: 12 May 2021

Published: 01 June 2021

Citation:

Fisher DAC, Fowles JS, Zhou A and Oh ST (2021) Inflammatory Pathophysiology as a Contributor to Myeloproliferative Neoplasms.

Front. Immunol. 12:683401. doi: 10.3389/fimmu.2021.683401

\section{Inflammatory Pathophysiology as a Contributor to Myeloproliferative Neoplasms}

\author{
Daniel Arthur Corpuz Fisher, Jared Scott Fowles, Amy Zhou and Stephen Tracy Oh* \\ Divisions of Hematology \& Oncology, School of Medicine, Washington University in St. Louis, Saint Louis, MO, United States
}

Myeloid neoplasms, including acute myeloid leukemia (AML), myeloproliferative neoplasms (MPNs), and myelodysplastic syndromes (MDS), feature clonal dominance and remodeling of the bone marrow niche in a manner that promotes malignant over non-malignant hematopoiesis. This take-over of hematopoiesis by the malignant clone is hypothesized to include hyperactivation of inflammatory signaling and overproduction of inflammatory cytokines. In the Ph-negative MPNs, inflammatory cytokines are considered to be responsible for a highly deleterious pathophysiologic process: the phenotypic transformation of polycythemia vera (PV) or essential thrombocythemia (ET) to secondary myelofibrosis (MF), and the equivalent emergence of primary myelofibrosis (PMF). Bone marrow fibrosis itself is thought to be mediated heavily by the cytokine TGF- $\beta$, and possibly other cytokines produced as a result of hyperactivated JAK2 kinase in the malignant clone. MF also features extramedullary hematopoiesis and progression to bone marrow failure, both of which may be mediated in part by responses to cytokines. In MF, elevated levels of individual cytokines in plasma are adverse prognostic indicators: elevated IL-8/CXCL8, in particular, predicts risk of transformation of MF to secondary AML (SAML). Tumor necrosis factor (TNF, also known as TNF $\alpha$ ), may underlie malignant clonal dominance, based on results from mouse models. Human PV and ET, as well as MF, harbor overproduction of multiple cytokines, above what is observed in normal aging, which can lead to cellular signaling abnormalities separate from those directly mediated by hyperactivated JAK2 or MPL kinases. Evidence that NFKB pathway signaling is frequently hyperactivated in a panhematopoietic pattern in MPNs, including in cells outside the malignant clone, emphasizes that MPNs are pan-hematopoietic diseases, which remodel the bone marrow milieu to favor persistence of the malignancy. Clinical evidence that JAK2 inhibition by ruxolitinib in MF neither reliably reduces malignant clonal burden nor eliminates cytokine elevations, suggests targeting cytokine mediated signaling as a therapeutic strategy, which is being pursued in new clinical trials. Greater knowledge of inflammatory pathophysiology in MPNs can therefore contribute to the development of more effective therapy.

Keywords: myeloproliferative neoplasms, myelofibrosis, cytokines, intracellular signaling, JAK2, NF kappa B (NFKB), tumor necrosis factor (TNF), Ruxolitinib 


\section{INTRODUCTION}

The $P h$-negative myeloproliferative neoplasms (MPNs) are chronic myeloid neoplasms, featuring an overproduction of one or more mature non-lymphoid cell lineages. A diversity of clinical presentations may include erythrocytosis, thrombocytosis, and/or myeloproliferation as the primary feature. These can be followed by progression to myelofibrosis as a primary or secondary disease phenotype, cytopenias and bone marrow failure, and/or transformation to secondary acute myeloid leukemia (sAML), for which the prognosis is dismal in the post-MPN setting. Many studies have elucidated that MPNs feature an inflammatory component to their pathophysiology, considered to be secondary to their neoplastic development, based on their relative paucity of somatically acquired driver mutations in inflammatory pathways. Inflammation, particularly in the bone marrow microenvironment, can be a factor in clonal dominance and in the progression of the disease, particularly inasfar as it promotes fibrotic transformation of the bone marrow and suppression of benign hematopoiesis, conferring a competitive advantage to the malignant clone. The inflammatory pathophysiology of MPNs, however, has the potential to be leveraged therapeutically for the development of new treatments and improved future therapy.

\section{CLINICAL ASPECTS OF MPNS SUGGEST INFLAMMATORY AS WELL AS NEOPLASTIC PATHOPHYSIOLOGY}

Ph-negative MPNs are associated with myeloproliferation, constitutional symptoms, and bone marrow fibrosis, which can also be observed in patients with chronic inflammatory diseases. The activating JAK2 V617F mutation is the most common driver mutation in MPNs. In polycythemia vera (PV) and essential throbocythemia (ET), the JAK2 mutation can sustain a condition of chronic inflammation (1-3), explaining the associated constitutional symptoms, thrombosis, and premature atherosclerosis observed in patients with these disorders (4-6). Furthermore, the increases in circulating levels of cytokines, chemokines, and reactive oxygen species (ROS) accumulation in chronic inflammatory states can lead to genetic instability, which may favor the development and progression of neoplasms (7). The current evidence suggests that MPNs are chronic inflammatory conditions in addition to neoplastic disorders, and that both processes contribute to the clinical manifestations and pathogenesis of the disease.

Several studies have suggested an association between autoimmune disorders and hematologic malignancies (8-10). A large population-based retrospective study by Kristinsson et al. (11) of 11,039 MPN patients and 43,550 matched controls found a significantly increased risk of MPN in patients with a prior history of autoimmune disease (11). The study found that individuals with a prior history of any autoimmune disease had a $20 \%$ increased risk of developing an MPN. When evaluated by individual autoimmune diseases, the study found a 2 -to 3-fold elevated risk of MPNs among patients with a history of immune thrombocytopenia purpura, Crohn's disease, polymyalgia rheumatica, giant cell arteritis, aplastic anemia, or Reiter's syndrome (11). These findings suggest that inflammation could be a predisposing factor for development of MPNs and that the overproduction of inflammatory cytokines associated with autoimmune diseases may play a role in the pathogenesis of MPNs (12).

Inflammation is considered a factor that may promote MPN disease development, progression and/or lead to poorer prognosis overall. The recent findings that clonal hematopoiesis is frequent among adult humans, that JAK2 $\mathrm{V} 617 \mathrm{~F}$ is among the most common mutations found in asymptomatic clonal hematopoiesis, and that, impressively, clonal JAK2 V617F is most frequently acquired in childhood or even in utero, suggest that some biological selective process is necessary to transform asymptomatic JAK2 V617F mutant clones into overt MPNs (13-17). Chronic inflammation in the bone marrow or in the systemic circulation could contribute to the slow selection for eventually pathogenic mutant clones. Further studies are needed, however, to elucidate the specific relationships between inflammatory disorders and MPNs.

A notable feature of MPNs is their diversity of disease phenotypes. MPNs may present as ET, PV, or PMF, often following years to decades of asymptomatic clonal hematopoiesis $(13,14,16,17)$. The malignant clones in the vast majority of MPN patients harbor mutations in JAK2, calreticulin (CALR), or MPL (18). Nearly all PV clones are JAK2 mutant, however, while ET and PMF clones may harbor mutations in any one of JAK2, CALR, or MPL. JAK2 mutant clones can give rise to any of the three disease phenotypes. MPN clones can differ in their propensity to induce inflammatory pathophysiology, which can, in turn, affect their disease phenotype. It has been observed that ex vivo erythroid cell colonies derived from patients with either ET or PV differed in their propensity to harbor elevated interferon $\gamma$ and STAT1 directed gene expression, which was more prevalent in ET versus PV derived colonies (19). This indicated that inflammatory signaling might alter disease pathophysiology even in the context of a common driver mutation.

JAK2 mutant homozygosity is substantially more common in PV and MF than in ET $(20,21)$. It has also been associated with more severe symptoms and increased risk of cardiovascular events in PV (22). In ET and PV, acute phase inflammatory proteins such as high sensitivity (hs)-CRP and pentraxin 3 (PTX3 ) were found to significantly correlate with $J A K 2$ V617F allele burdens of greater than 50\% (23-25). Hs-CRP levels were shown to be increased in MPN patients compared to normal controls, and independently associated with shortened leukemia free survival in myelofibrosis (MF) patients (26). Increased levels of hs-CRP were associated with an increased risk of thrombosis, although conversely, high PTX-3 levels were associated with a lower rate of thrombosis (23). Importantly, however, JAK2 V617F allele burdens of greater than $50 \%$ in MF patients have also been associated with favorable responses to ruxolitinib (27), suggesting that MPN patients with elevated hs-CRP or PTX-3 may benefit from aggressive JAK inhibitor therapy. 
Consistent with evidence of elevated inflammation, JAK2 mutant homozygosity in $\mathrm{PV}$ or $\mathrm{ET}$ increases risk of transformation to $\mathrm{MF}$ (28). In contrast to mutant JAK2, mutant CALR and $M P L$ alleles almost never develop homozygosity $(29,30)$. The contribution of JAK2 mutant homozygosity to the inflammatory pathophysiology of MPNs remains obscure, but might contribute to differences between outcomes of JAK2 mutant ET or MF patients versus others. In PMF, survival (either overall or leukemia free) is inferior in the $J A K 2$ mutant patient population (as compared to MPL or CALR mutant patients; although triple negative, or $3 \mathrm{~N}$, PMF shows even worse survival) $(31,32)$. The observation of typically greater $\mathrm{NF \kappa B}$ activation in hematopoietic stem and progenitor cells (HSPCs) from JAK2 mutant MF patients (33) is suggestive of more severe inflammation, which may in turn contribute to poor outcomes. More widespread expression of mutant JAK2 versus $M P L$ or CALR (34) among hematopoietic cells may contribute to greater inflammation in JAK2 mutant patients as well.

Despite evidence of inflammatory pathophysiology contributing to poor outcomes in MPNs, specifically to the development of secondary MF and thromboses (3, 5, 23, 25, $26,28,35,36)$, other factors are known to influence outcomes in MPNs, some of which may have divergent effects from those caused by inflammation. Epigenetic and RNA splicing related mutations are well recognized as predictive of adverse outcomes in MPNs $(18,31)$. It is notable that low, rather than high, JAK2 V617F allele burdens at diagnosis have been correlated with shortened leukemia-free survival in $\operatorname{PMF}(37,38)$. Low JAK2 V617F allele burdens at diagnosis may be associated with anemia and cytopenias in MF (38), and possibly with epigenetic mutations producing prognoses more similar to those of triple negative, or $3 \mathrm{~N}, \mathrm{PMF}(32,39)$. In PV, low JAK2 V617F allele burdens at diagnosis are also common in younger patients who frequently present with thrombotic events $(40,41)$.

\section{CYTOKINES ARE ELEVATED IN ALL CHRONIC PHASE MPNS IN COMPARISON WITH HEALTHY AGED INDIVIDUALS}

Multiple studies that investigated cytokine levels in MPNs have now produced data showing widespread cytokine elevations in ET, PV, and PMF, and correlations with disease features and outcomes (Tables 1 and 2). These studies have identified not only the cytokine elevations most associated with particular disease phenotypes, but also with blast transformation of a chronic phase MPN, or with prognosis. The wide variation in the studies in terms of technology, disease subtype, and specific cytokines measured, poses a challenge for hypothesis generation. Regardless, underlying concepts are coming into focus, namely that: 1) elevated cytokines are observed in MPN patients of all subtypes compared to healthy individuals; 2) the elevated cytokine profiles between subtypes appear distinct in composition or magnitude albeit overlapping among different MPN diagnoses on the level of individual cytokines. Evidence of elevated cytokine levels in MPN patients began to emerge over 30 years ago, with studies relying predominantly on ELISA and/or semiquantitative real time PCR of a small collection of targets. The development of multiplex array-based and single cell technologies in recent years has allowed researchers to interrogate large panels of cytokines to further illuminate the connections between inflammatory cytokines and other pathophysiologic features of myeloid malignancies.

In studies that correlated cytokine levels from PV and ET samples with disease features, IL-2, s-IL-2R, and IL-6 correlated with MF transformation from both PV and ET (50). Additionally, CRP correlated with thrombosis and JAK2 V617F burden in a combined PV/ET cohort (23). In ET where overproduction of platelets is a main feature, a study observed a correlation with thrombocytosis and TNF levels (47).

Patients with primary myelofibrosis (PMF) have been shown to share both clinical symptoms and laboratory abnormalities with patients with systemic inflammatory response syndrome, such as elevation in the erythrocyte sedimentation rate, $\mathrm{C}$ reactive protein (CRP), IL-1 $\beta$, IL-6, IL-8, and TNF (54). High plasma levels of IL- 6 and IL- 8 were found to be significantly associated with severity of constitutional symptoms in PMF patients by Tefferi et al. (43) Elevations of IL-2, and sIL-2R, Il6 , IL-8, and $\beta 2$-microglobulin, have been associated with blast transformation of CML or $\mathrm{Ph}$ - MPNs, based on several studies $(43,50,51,55)$. IL-8, also known as CXCL8, is a CXC family cytokine found to be expressed by HSPC in MF (48) and de novo AML (56) patients. High levels of IL-8 were associated with both poor overall and leukemia-free survival, and transformation to sAML, when assayed in blood plasma from MF patients (43). IL8 has thereby been hypothesized to be a potential surrogate for CD34+ cell burden in MF, and hence a possible risk marker for incipient transformation to sAML (48). Tefferi et al. also found plasma IL-12, IL-15, IP-10, and circulating IL-2R, to be independent markers of poor survival, as well as IL-8 (43).

The prognostic potential of cytokines in PV was addressed in 2012 by Vaidya et al., revealing a different profile from what was observed for MF (44). Thirty cytokines were measured from plasma samples from 65 patients using the same Luminex technology as in the preceding study by Tefferi et al. for MF (43). A univariate analysis showed association of multiple cytokines with inferior overall survival in PV, but CCL4/MIP$1 \beta$ alone remained associated in a multivariable analysis. Fibrotic transformation was associated in a univariate analysis with elevations in IL-1 $\beta$, IL-5, IL-6, IL-10, IL-12, IL-15, IL-17, and IP-10 (44).

Verstovsek et al. showed that levels of several cytokines from 25 patients enrolled in the Phase 1-2 clinical trial of ruxolitinib for MF, before and 28 days-post treatment decreased significantly (57). Reductions of CRP, IL-1RA, CCL4/MIP-1 $\beta$, TNF, and IL-6 were associated with decrease in the composite symptom score of patients (57). Pardanani et al. identified in MF patients from two different clinical trials of pomalidomide for MF-associated anemia, that patients with high levels of sIL-2R, IL-8, IL-15, MCP-1, and VEGF at baseline had significantly lower rates of anemia response to treatment (42). 
TABLE 1 | Selection of inflammatory cytokines elevated in plasmas of MPN patients of all disease stages.

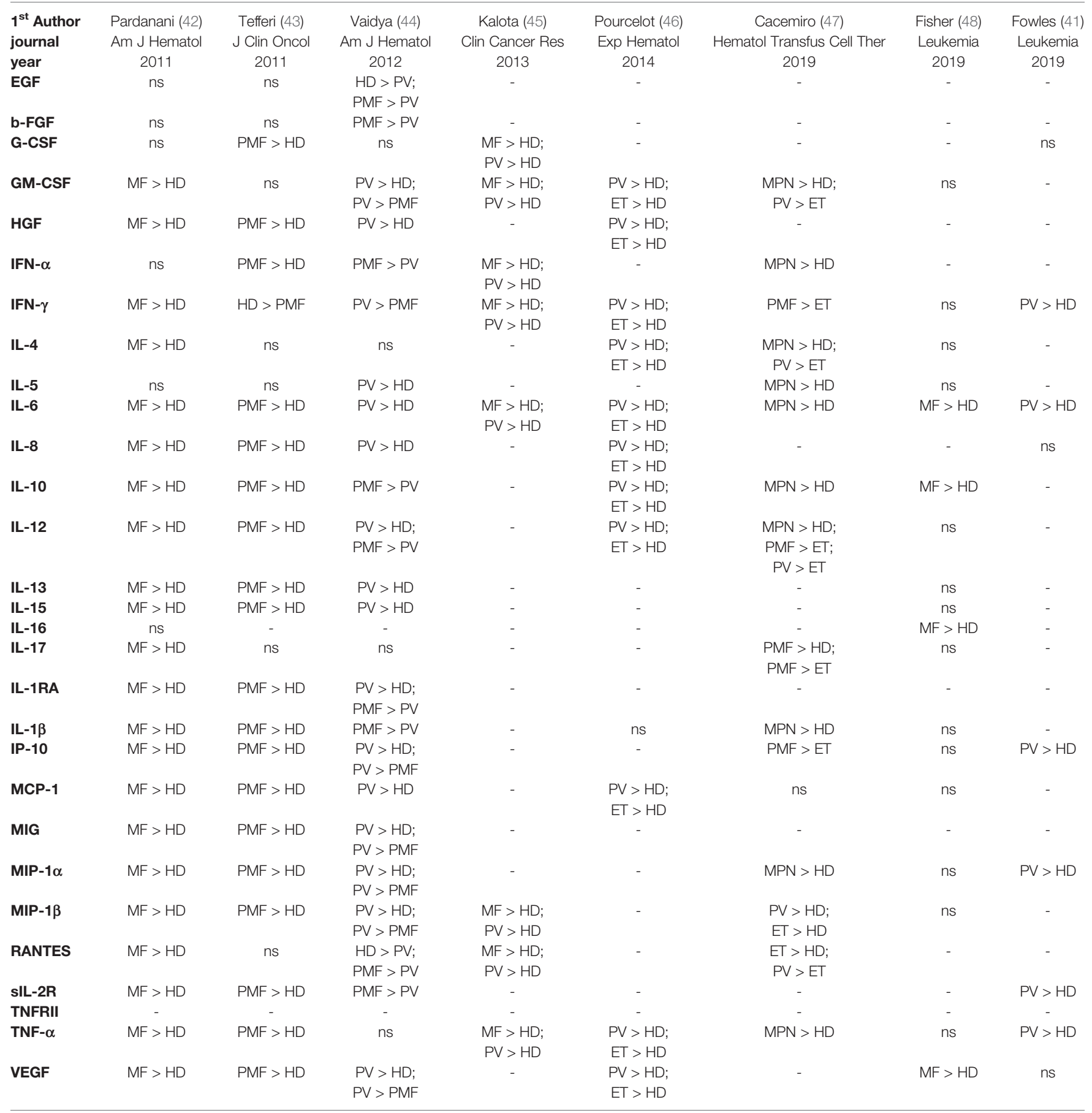

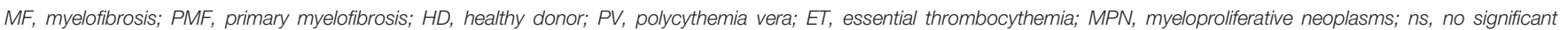
differences between sample types; ">", first sample type is significantly elevated compared to second sample type; "-", not in assay.

Inflammation has been shown to increase with age, consistent with changes in hematopoiesis observed in healthy aging. Although much less frequently, MPN can occur at younger ages. In 2019, a study by the authors examined the relationship of age in PV patients with both inflammation and genomic mutation profile (41). Comparing plasma from 16 young PV patients (age $\leq 45$ years) with 12 old PV patients (age $\geq 65$ years) that were all within 1.5 years of diagnosis, the same cytokines were significantly elevated compared to age-matched healthy donors (10 young and 7 old). When comparing the fold change based on their respective age-matched donors, old PV patients exhibited an exacerbated elevation of cytokines compared to young PV patients. Overall mutational burden increased with age as expected, and secondary non-JAK2 driver mutations were 
TABLE 2 | Cytokine correlations with disease features and outcomes in MPNs

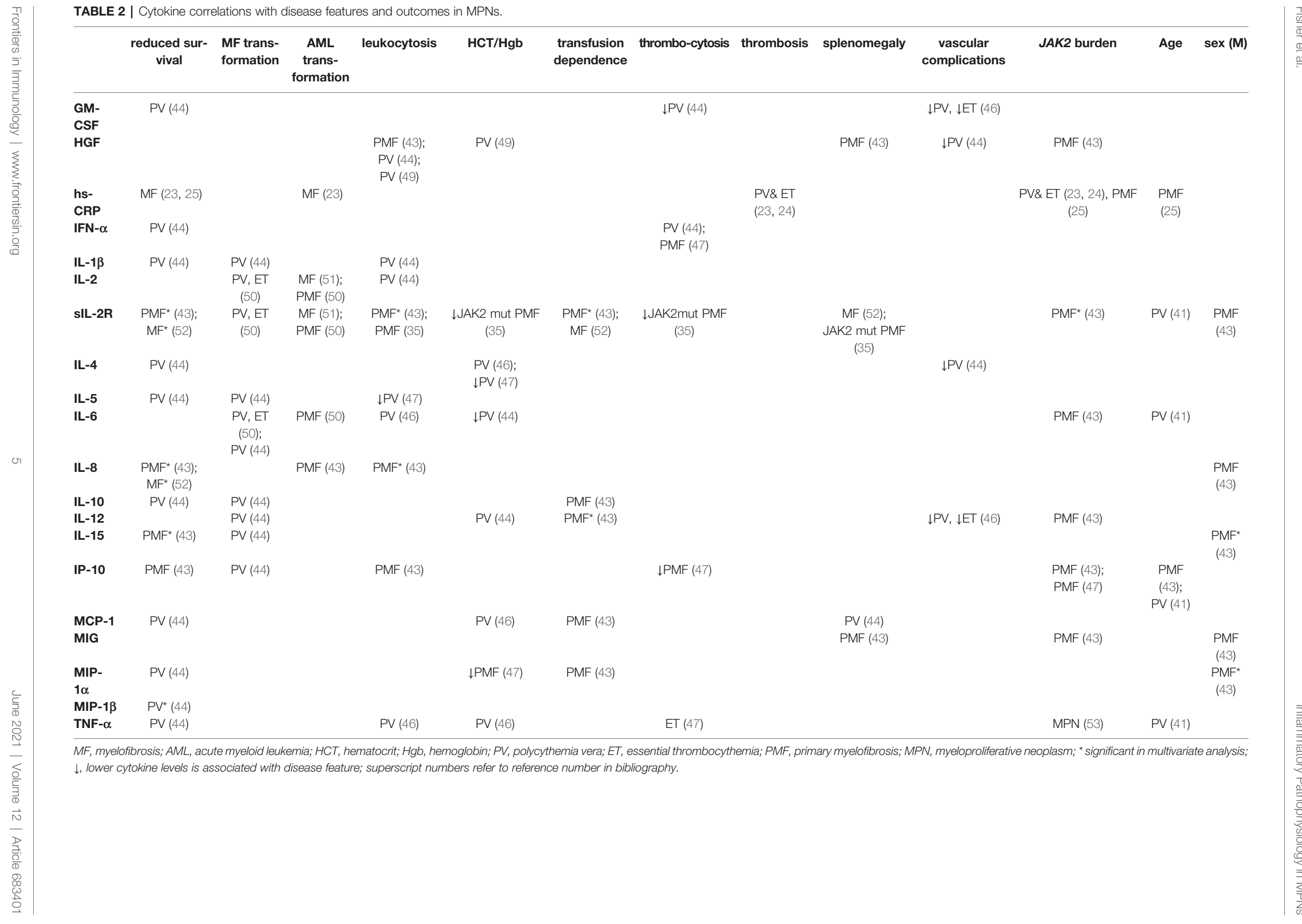


found in 9/10 old PV patients, in contrast with young PV patients, where JAK2 V617F appeared to be the only diseaserelated mutation present (41). Together, this data suggests two important concepts for MPN pathophysiology: First, that PV patients exhibit elevated inflammatory cytokine production regardless of age. Second, that the more pronounced elevation of cytokines observed in old PV patients could be attributable to age and/or the presence of secondary mutations. It is important to note that in this study no predominance of non-JAK2 mutations preceding JAK2 V617F was observed. This suggests that the increase in MPN-related mutational burden might not be a mere function of age, but also a result of the JAK2 mutation itself, as suggested by findings that JAK2 V617F may indirectly promote genomic instability (58).

Taken together, these studies provide evidence that inflammatory cytokine levels are elevated in MPNs compared to healthy counterparts, that this elevation can be seen even among relatively young MPN patients, and that other signaling pathways or factors may be involved besides JAK-STAT signaling. Furthermore, plasma cytokines levels in MF and sAML patient samples, assayed by V-PLEX human cytokine 30-plex assay, demonstrated that sAML cytokine levels were similar to MF levels (48). Therefore, the pattern of elevation of plasma cytokines observed in chronic MPNs persists in sAML, despite the extremely altered cellular composition of AML versus chronic MPNs.

\section{HYPERACTIVATION OF JAK2 OR MPL CAUSES MYELOPROLIFERATION, CYTOKINE PRODUCTION, AND MYELOFIBROSIS}

The $P h$-negative myeloproliferative neoplasms (MPNs), polycythemia vera (PV), essential thrombocythemia (ET), primary or idiopathic myelofibrosis (PMF), and secondary myelofibrosis (MF, secondary to PV or ET), share a common etiology in hyperactivation of the kinase JAK2 in the hematopoietic stem and progenitor cell (HSPC) compartment of a malignant clone. Genomic studies of MPNs have revealed that nearly all cases of PV harbor mutations in the gene encoding JAK2 itself, with the specific hyperactivating JAK2 V617F mutation being present in over $90 \%$ of cases of $\mathrm{PV}$, and slightly over half of all studied cases of ET and PMF (31, 40, 59,60 ). Roughly $5-10 \%$ of ET and MF patients harbor mutations in the MPL gene, which encodes the cell surface receptor for thrombopoietin (TPO), which signals intracellularly by binding to and activating JAK2 kinase. A greater portion, 30-35\% of ET and MF patients, harbor mutations in calreticulin $(C A L R)$, a multifunctional protein typically resident in the endoplasmic reticulum, but occasionally exposed at the cell surface $(29,30$, 34). Mutant versions of CALR protein contain a neomorphic Cterminal domain (resulting from a frameshift in the genomic DNA sequence) that complexes MPL molecules at the cell surface and predisposes them to constitutive signaling activity
(61). Therefore, in almost all cases of MPNs, the malignant clone harbors a mutation conferring a constitutive activation of JAK2 activity in the HSPC population, and throughout derivative malignant hematopoiesis (Figure 1). It is not clear if this is true in the case of every MPN patient, as there exist rare triple negative $(3 \mathrm{~N})$ cases lacking mutations in any of the JAK2, MPL, or CALR genes. Some of these $3 \mathrm{~N}$ cases, however, have been found to harbor mutations in genes such as $C B L$ and $S H 2 B 3$ / LNK $(62,63)$, which confer enhanced JAK2 activity by removal of inhibition; hence it is likely that all $P h$-negative MPN cases include constitutive JAK2 activity in the malignant clone (60). JAK2 inhibition, most frequently with ruxolitinib, the first JAK inhibitor approved for treatment of MF, remains the best available therapy and standard of care for many MF patients today, and provides clinical benefits to selected PV (and some ET) patients as well (64-70).

The identification of disease-driver mutations in $M P L$ and $C A L R$, in addition to those in $J A K 2$, confers clues to the molecular pathophysiology underlying the diversity of MPN phenotypes. MPL mutations in MPNs are activating mutations that facilitate activation of JAK2 kinase by MPL receptor. The $M P L$ gene is expressed in HSPCs, including stem cells and early myeloid progenitors, in all stages of the megakaryocytic lineage, and in a subset of monocytic lineage cells, some of which may be fibrogenic (71). These cells respond to TPO by activating JAK2, which phosphorylates the transcription factors STAT3 and STAT5, to transcriptionally active forms capable of mediating cell-type-specific transcriptomic profiles $(72,73) . M P L$ and $C A L R$ mutations are notably not observed in PV, presumably because the $M P L$ gene is not expressed in erythroid progenitors, the proliferation of which is normally driven by erythropoietin rather than TPO. A mouse model of Mpl hyperactivity in vivo, however, is sufficient to produce bone marrow fibrosis that resembles that observed in MF: Tpo treatment of mice induces bone marrow fibrosis, and this has been used as a model to study this pathophysiologic process, albeit in the absence of a malignant clone (74). This stands in contrast to mouse models expressing MPN-derived mutations in JAK2 and CALR homologs at physiologic levels, which exhibit phenotypes resembling PV or ET, with little if any bone marrow fibrosis (75). In humans, progression of PV or ET to secondary MF often occurs over a number of years greater than the lifespan of a mouse (28).

The specific pathophysiology of myelofibrosis has long been hypothesized to be reactive, since the bone marrow stromal cells are non-malignant, with an important role played by cytokines secreted from malignant cells $(54,76)$. In the Tpo induced model of bone marrow fibrosis, the cytokine transforming growth factor beta (Tgf- $\beta$ ) was found to be essential to the development of the fibrotic phenotype (74). The essential lesson from this study was that Tpo-responsive cells (hence, $\mathrm{Mpl}$ expressing) directed bone marrow fibrosis non-cell-autonomously via the production of another cytokine. This illustrates the inflammatory hypothesis of MPN pathophysiology, a hypothesis that has been applied to other cancers as well: namely, that inflammation, particularly via inflammatory cytokines, is a major driver of disease phenotype. 
A
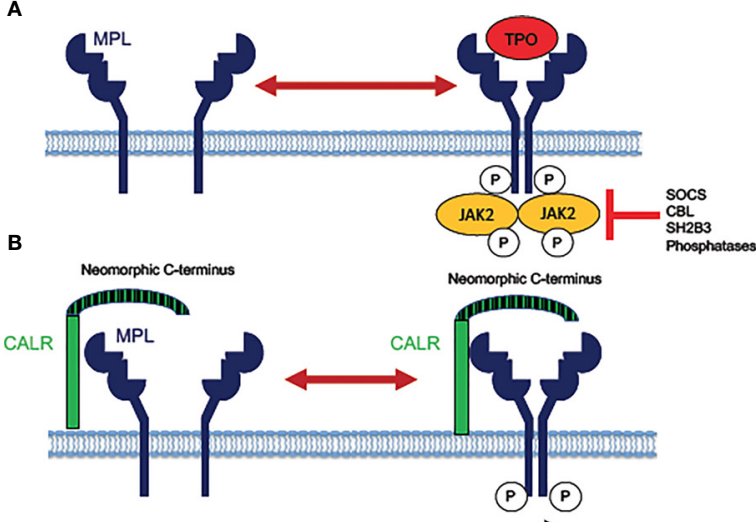

c

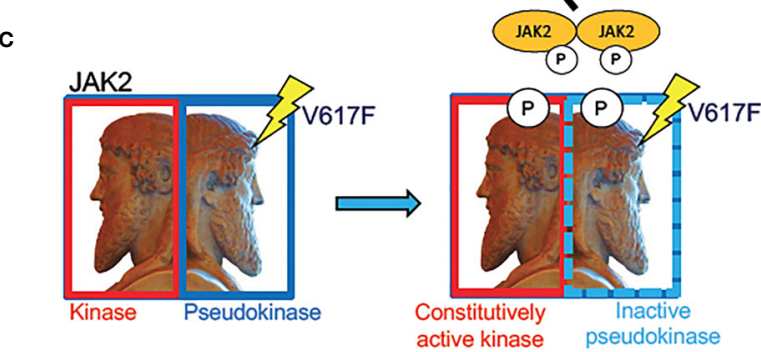

D

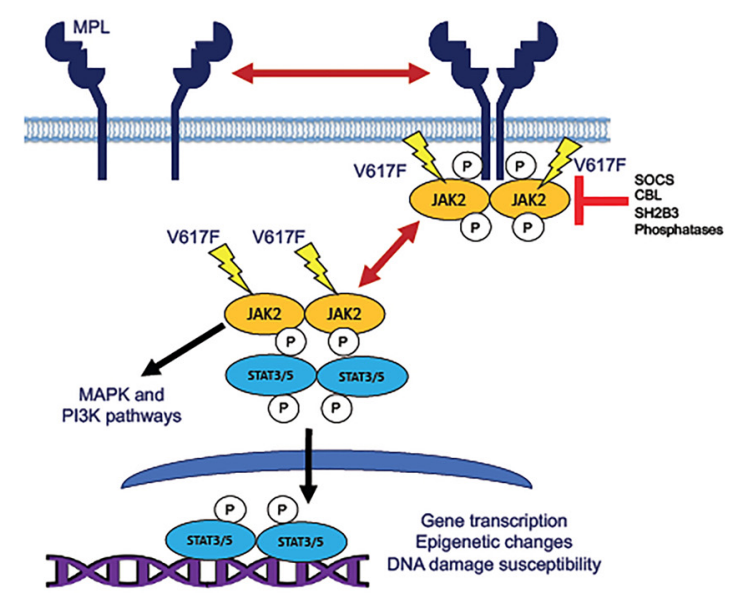

FIGURE 1 | Mechanisms of JAK2 activation by MPN driver mutations. (A) Normal mechanism for receptor activation of the human thrombopoietin (TPO) receptor MPL (myeloproliferative leukemia proto-oncogene). MPL, expressed in HSPC and megakaryocytic lineage cells, exists in an equilibrium between inactive monomers and active homodimers. Binding of the monomeric ligand TPO stabilizes dimer formation, allowing phosphorylation of the receptor by dimeric JAK2 tyrosine kinase. This step initiates intracellular signaling downstream of active JAK2. The active receptor-kinase holocomplex is subject to inhibition by several inhibitor molecules, notably SOCS (suppressor of cytokine signaling) family proteins, tyrosine phosphatases, and the adaptor protein SH2B3 (also known as LNK, lymphocyte linker protein). Mutations in genes encoding these various inhibitory molecules are rare driver mutations in MPNs, which lead to JAK2 hyperactivation by removal of physiologic inhibition. (B) Activation of JAK2 signaling by mutant CALR. The single-pass transmembrane protein CALR (calreticulin) is a calcium-binding chaperone protein that normally recycles between plasma and intracellular membranes in the secretory pathway. Mutated CALR acquires a neomorphic C-terminus (depicted as striped), which is capable of binding to and dimerizing MPL, consequently producing signaling-active MPL homodimers, which recruit and activate JAK2, in the absence of TPO binding. CALR mutations in MPN are therefore hypothesized to have similar effects to activating MPL W515L/K mutations, which are present in roughly $10 \%$ of ET and MF patients. (C) Effect of the JAK2 V617F mutation. JAK2 (Janus kinase), depicted as the ancient Roman god Janus (sculpture in the Vatican Museum, Rome), contains homologous kinase and pseudokinase domains, the pseudokinase being inhibitory to the kinase. V617F mutation in the pseudokinase domain inactivates the inhibition, producing a constitutively active (autophosphorylated) kinase. (D) Direct activation of JAK/STAT signaling by active JAK2. Mutant JAK2 (typically V617F) dimerizes MPL and other cytokine receptors, rendering the receptor active even in absence of a bound ligand. The active receptor-bound JAK2 phosphorylates STAT3 and STAT5 homodimers, which then translocate to the nucleus to activate transcription. Unlike MPL and CALR mutations, JAK2 mutations enable constitutive JAK2 activity even in cells that do not express MPL. Mutant JAK2 has been shown to promote epigenetic changes and increase the potential for unrepaired DNA damage. Active JAK2 collaterally activates MAP kinase (MAPK) and PI3 kinase (PI3K) signaling pathways independently of STAT3 and STAT5. 
Furthermore, the hyperabundance of inflammatory mediators that is present in myeloid neoplasms is not confined to circulating cytokines. Cell-contact-mediated inflammatory activation is certainly also a feature of these diseases. In the case of MF, cell-contact-mediated inflammatory activating ligands, such as FAS and the endogenous toll-like-receptor ligands S100A8 and A100A9, have been found to be upregulated at the gene expression level in the malignant CD34-expressing HSPC population $(48,77)$. This is important because, in MPNs, the HSPC population is not only the diseasepropagating population from which the malignant clone initially arises, but also because it is a malignant population that remains present over the course of years in the chronic (ET or PV) phase of the MPN, and hence must be at least partly responsible for effecting phenotypic transformation, such as from ET or PV to MF (78). In MPNs, the entire compendium of malignant pathophysiology must ultimately originate from the stem cell population.

In contrast to the dependence of MPN pathophysiology on the actions of malignant HSPCs, MPNs are also panhematopoietic diseases, involving the entire hematopoietic system of the patient, as well as the niche environments supporting hematopoiesis, such as the bone marrow and splenic stroma. Prominent features of MF pathophysiology include HSPC mobilization from the bone marrow, and consequent extramedullary hematopoiesis in the spleen (and occasionally in the liver), producing marked splenomegaly. Therefore, the roles of multiple hematopoietic cell niches need to be considered in the total extent of pathophysiology of MPNs, as components of the affected hematopoietic system.

\section{MF CYTOKINE OVERPRODUCTION DEPENDS ON SIGNALING ABNORMALITIES BEYOND JAK-STAT}

MPN pathophysiology is predominantly dependent on the common feature of hyperactivation of JAK2 kinase. Therefore, it is of interest to determine to what extent the inflammatory features of MPNs are directly, or indirectly, dependent on JAK2 activity. This is also important because JAK2 inhibition, as a therapeutic modality for MPNs, does not greatly or reliably reduce the malignant clonal burden or extent of bone marrow fibrosis (68, 79,80 ). Therapeutic JAK2 inhibition with ruxolitinib was observed to result in reductions of multiple plasma cytokines in MF patients within the first month of treatment (57). Ruxolitinib treatment of MF patients for periods from one month to over a year, however, was observed not to revert plasma cytokines to the low levels seen in healthy control plasmas (48). Therefore, ruxolitinib can be said to provide a partial, but incomplete, reduction of inflammatory pathophysiology in MF. This conclusion raises the important question of whether longstanding MPN pathophysiology has activated signaling pathways that cannot be restored to their normal state by ameliorating the primary signaling defect of JAK2 hyperactivation. Multiple cytokines significantly elevated in MF plasmas activate downstream signaling other than via JAK-STAT. These included TNF, which is known to activate multiple signaling pathways, including pro-apoptotic signaling and the canonical NFKB pathway (81). Other studies identified pathologic production of TNF in ET, PV, and sAML, as well as in de novo AML, implying non-JAK/STAT signaling hyperactivations almost certainly occur across the spectrum of MPNs $(33,41,53,82)$.

Our group has utilized mass cytometry (CyTOF) to survey both intracellular signaling in MF and sAML (33) and cytokine production in human MF patient blood cells ex vivo (48). A survey of intracellular signaling identified frequent elevations of MAP kinase, PI3 kinase, and NFKB pathway signaling markers in MF and sAML patients HSPCs, and in some other myeloid populations such as monocytes (33). Independent gene expression studies corroborated evidence for supranormal NFאB signaling, as well as Notch and p53/apoptotic signaling, in PMF $(33,77,83)$. Evidence for NFKB signaling hyperactivation was also observed in $M P L$ W515L model mice (84), and in Jak2 V617F model mice with loss of Dnmt3a, which showed a myelofibrosis-like phenotype (85).

Since MF patients frequently exhibit mobilization of CD34+ hematopoietic stem and progenitor cells (HSPC) from the bone marrow to the peripheral blood and spleen, it is possible to study cells occupying a spectrum of hematopoiesis from stem cells to more mature cells, using blood cells from MF patients, and comparing these to cells with comparable immunophenotypes in healthy control bone marrow and peripheral blood. Using the mass cytometry approach, our group was able to analyze cytokine production throughout hematopoietic cell populations ex vivo in MF patients versus healthy controls (48). Among cytokines surveyed by mass cytometry, a subset were identified that were inducible by TPO and TLR ligands, most of which were also inducible by TNF: these included TNF itself, IL-6, and IL-8/ CXCL8, all previously implicated in MPN pathophysiology (48). This result suggests that in vivo overproduction of these cytokines is supported by combined JAK2 and NFKB signaling hyperactivations. Basally supranormal, or constitutively elevated, production of these cytokines in MF cells, was not invariably sensitive to suppression by ex vivo ruxolitinib. Instead, inhibitors of $\mathrm{NF \kappa B}, \mathrm{MEK}$, and p38MAPK, were more effective than ruxolitinib at reducing basal levels of TPO/TLR/TNF inducible cytokines. Another subset of MF overproduced cytokines, notably including TGF $\beta$ and VEGF, did not show any responsiveness to TPO, TLR ligands, TNF, or ruxolitinib. Their basal levels, ex vivo, were likewise either unaffected or slightly elevated by inhibitors of NFKB, MEK, p38MAPK, or JNK. This second set of cytokines was not frequently co-expressed with the first set at the single cell level, while the TPO/TLR/TNF inducible cytokines were frequently coexpressed in individual MF monocytes (Figure 2). This suggests that overproduction of TGF $\beta$ and VEGF is directly driven by entirely different signaling pathways from TNF, IL-6, and IL-8/ CXCL8, and which are separate from JAK-STAT, NFKB, MAPK, or JNK pathways.

Plasma cytokines elevated in the MPL W515L retroviral transplant mouse model of MF were also reduced by ruxolitinib, although not to the low levels observed in control 
A

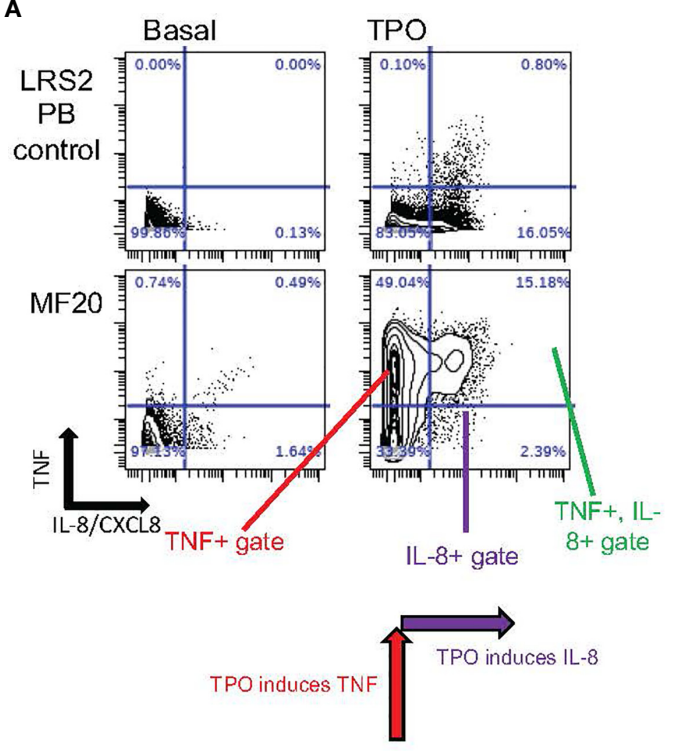

B

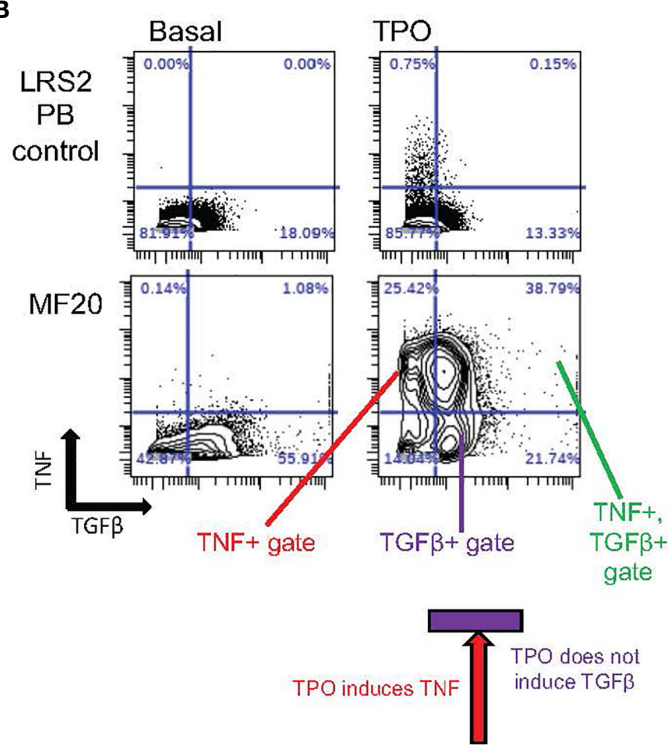

C

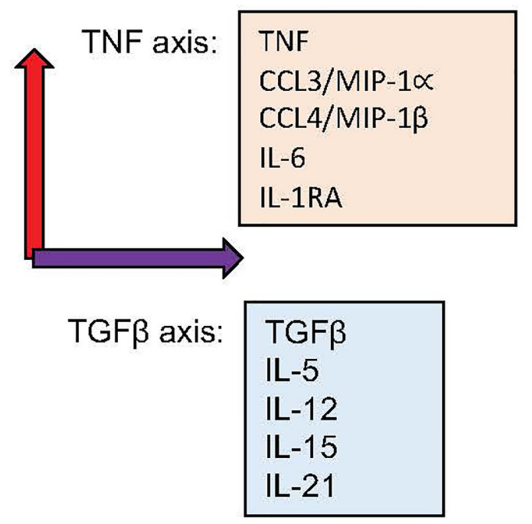

Co-expression/regulation with TNF and TGF $\beta$ :

\begin{tabular}{ll}
\hline IL-8 IL-10 \\
\hline
\end{tabular}

Co-expression/regulation with
neither TNF nor TGF $\beta$ :

IFN $\gamma \quad$ VEGF

FIGURE 2 | Distinct coexpressed groups of cytokines overproduced in MPNs. Data specific to MF, also utilized in Fisher et al. (48). (A, B) Presence or absence of tandem regulation of cytokine induction by TPO. Biaxial plots show in rows (from top to bottom) ex vivo cell samples from healthy control blood and blood from the JAK2 V617F mutant MF patient MF20. Columns show cytokines as identified in cells by mass cytometry (CyTOF) after 4-hour incubation either without stimulation (Basal) or stimulated by TPO. (A) In monocytes, TNF (Y axis) showed coexpression with IL-8/CXCL8 ( $X$ axis) when induced by TPO. Combined induction is illustrated by schematic below lower right plot. (B) TGF $\beta$ ( $X$ axis) showed minimal basal coexpression with TNF ( $Y$ axis) in monocytes. TPO stimulation, however, induced TNF but not TGF $\beta$, as illustrated by schematic under lower right plot. (C) Schematic depicting "axis" groups of cytokines overproduced in MF myeloid cells ex vivo. The majority of cytokines could be separated into TNF or TGF $\beta$ "axis" groups (related to biaxial plots in A, B), based on co-expression with either TNF or TGF $\beta$ after stimulation with TPO, TNF, or a TLR receptor ligand (R848 or PAM3CSK4), with Pearson R>0.25 (48). Of 15 cytokines assayed by CyTOF in Fisher et al. (48), only VEGF and IFN $\gamma$ failed to demonstrate coexpression with either TNF or TGF $\beta$, while IL-8/CXCL8 showed some evidence of coregulation with both (R>0.25).

mice (86). Cytokine levels were further reduced in this mouse model by BET bromodomain protein inhibitor JQ1, which reduced NFKB-associated gene expression, in combination with ruxolitinib (84). Since multiple cytokines are known to be inducible by $\mathrm{NFKB}$, this pathway is an obvious candidate for a direct inducer of cytokine expression in MPNs.

Tgf- $\beta$ mediated fibrosis in Tpo-treated mice has been linked to suppression of GATA-1 expression in megakaryocytes (87). However, the relationship of this model to human MF is uncertain, not only because it lacks a malignant clone, but also because it can be produced in NOD/SCID mice lacking a functional immune system and defective in cytokine secretion from monocytes (88); whereas monocytes, as well as megakaryoblasts, were observed to produce TGF $\beta$ in human MF (48). In contrast, pharmacologic inhibition of Aurora kinase A (AURKA) reduced plasma Tgf- $\beta$ and bone marrow fibrosis in the MPL W515L retroviral transplant mouse model of MF (89). This result cannot be compared to those obtained in the same mouse model with ruxolitinib and/or JQ1, as Tgf- $\beta$ was not among the cytokines assayed in those studies $(84,86)$. Therefore, the signaling mediators directly driving TGF $\beta$ and VEGF overproduction in MF remain unknown. 


\section{TNF IS IMPLICATED IN CLONAL DOMINANCE IN MPNS}

MPNs are clonal diseases of the hematopoietic compartment, but the mechanisms for clonal expansion are not fully elucidated. Plausible hypotheses include that the molecular events driving pathogenesis, such as mutations that constitutively activate JAKSTAT signaling, either confer growth advantage to HSPCs compared to their wildtype counterparts under normal conditions, or can be protective against additional environmental factors related to aging, such as declining hematopoietic stem cell (HSC) functionality or inflammation $(12,54,90)$. The TNF receptors TNFRSF1a and TNFRSF1b (also known as TNFR1 and TNFR2) activate different signaling pathways downstream of TNF binding (Figure 3), the former being associated with apoptosis and the latter with proliferation (81). Notably, TNFRSF1a, but not TNFRSF1b, contains an intracellular protein-protein binding domain known as a "death domain" (DD), which provides an essential scaffold for recruitment of the apoptosis-inducing multiprotein "Complex II”, or Death Inducing Signaling Complex (DISC), which can be activated by TNF $(81,91)$.

TNF can activate the canonical NFKB pathway, which is associated with myeloproliferation, both in myeloid neoplasms and in "stress" or "emergency" hematopoiesis following a hematopoietic insult such as the systemic inflammation resulting from an infection (92). Nonetheless, TNF has been observed to mediate substantial myelosuppressive effects by its direct action on hematopoietic stem and progenitor cells (HSPCs). Tnf can cause bone marrow failure and induce leukemic clonal evolution in mouse models of Fanconi anemia $(93,94)$. Furthermore, a recent study has shown that Tnf injected into normal, healthy mice is acutely toxic to myeloid progenitor cells and granulocytes, causing cell death by a combination of apoptosis and necroptosis, but that HSC are resistant to this Tnf toxicity (95). It has been hypothesized in several studies that malignant HSC from MPNs or leukemic initiating cells (LICs) in AML may harbor cell-autonomous mechanisms enabling these cells to further resist toxic or myelosuppressive effects of TNF acting on their non-malignant counterpart cells $(53,82,96,97)$.

The duality of TNF as an endogenous factor, which could potentially be either myelosuppressive or myeloproliferative, has led to hypotheses that this cytokine could play a major role in myeloid neoplasms, in the manner of promoting clonal dominance by exerting a myelosuppressive role on benign hematopoiesis while simultaneously exerting a myeloproliferative role on malignant hematopoiesis. This could be particularly crucial for chronic MPNs, where clonal dominance develops despite the malignant clone producing (mostly) functional mature myeloid cells. This feature of MPNs stands in contrast to AML or myelodysplastic syndromes (MDS), in which maturationdefective abnormal myeloid cells accumulate in a manner that can progressively crowd the normal hematopoietic niche out of existence. Therefore, a mechanistic hypothesis explaining the development of clonal dominance in MPN pathophysiology is necessary.
TNF is elevated in human MPN patient samples and is also elevated in JAK2 V617F mouse models of MPN; notably, Fleischman et al. showed that PV, ET, and MF patients all had higher TNF levels in blood plasma than healthy controls, and that TNF levels correlated with JAK2 V617F burden (53). Colony formation assays in methylcellulose revealed that whereas normal cells were inhibited by TNF, JAK2 mutant cells were either resistant or stimulated by TNF (53). In colony assays from $\operatorname{Tnf}$ knockout mice with or without retroviral expression of JAK2 V617F, the former clonal expansion observed in JAK2 mutant cells in colony formation assays was limited. Additionally, in the mouse model, lack of Tnf did not prevent MPN development, but did severely limit the expansion of JAK2 mutant cells. These data suggest that JAK2 V617F HSPCs can both induce production of TNF and protect from its suppressive effects, thereby promoting clonal expansion (53). Simultaneously, the data suggest that TNF is not strictly necessary for development of an MPN disease phenotype. Recently, a study with induced pluripotent stem cell-derived CD34+ cells from a PV patient showed that $J A K 2 \mathrm{~V} 617 \mathrm{~F}$ not only induces inflammation through IFN $\gamma$ and NFKB pathways, but also protects from DNA damage due to inflammation via upregulation of dualspecificity phosphatase 1 (DUSP1) (98). The authors also observed that JAK2 V617F-expressing cells only exhibited partial activation of ATM-related DNA damage checkpoint and $\mathrm{p} 38 / \mathrm{JNK}$ stress pathway signaling under inflammatory conditions (98). In this system, expression of TNF, IFN $\gamma$ or TGFß alone was insufficient for the induction of pro-fibrogenic chemokines CXCL9 and CXCL10, while the expression of TNF combined with IFN $\gamma$ or all three cytokines produced a strong pro-fibrogenic response (98). By implication, a fibrogenic response could be produced by TNF plus IFN $\gamma$ without artificial overexpression of TGFß, but none of the three cytokines alone sufficed to produce a strong fibrogenic response.

Clonal expansion mediated by TNF was reported in AML mouse models, showing that leukemic initiating cells (LICs) harbored constitutive NFKB activity due to an autocrine positive feedback loop with TNF $(82,97)$. NFKB signaling was bolstered by increased proteasome activation, which resulted in enhanced degradation of $\mathrm{I} \kappa \mathrm{B} \alpha$, a negative regulator of $\mathrm{NF} \kappa \mathrm{B}$. This TNF/NFאB activity which increased LIC frequency in AML cells was not present in normal HSCs (82). Volk et al. also found that the administration of exogenous TNF had opposite effects with leukemic cells versus normal HSPCs in colony forming assays, where leukemic cells expanded and HSPCs were repressed (97), an analogous result to that obtained by Fleischman et al. with MPN HSPCs (53).

In 2011, a double knockout mouse for both Tnfrsfla and Tnfrsf1b (encoding Tnfr1 and Tnfr2, respectively) was compared by Pronk et al. to either receptor knockout alone, showing for the first time that in vivo suppression of HSC cycling by TNF requires the expression of both receptors (99). A separate study in the same year showed that deletion of both Tnf receptors in mice provided a partial rescue of the combination of apoptosis and necroptosis produced in HSPCs by deletion of the Tgf- $\beta$ activated kinase (Tak1), which inhibits cell death pathways 
A

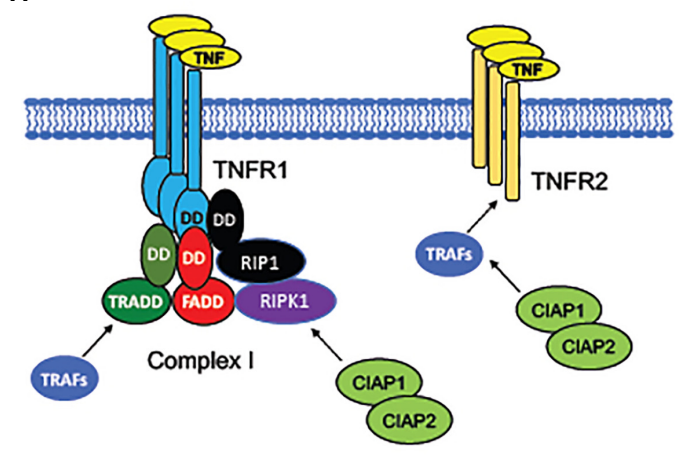

c

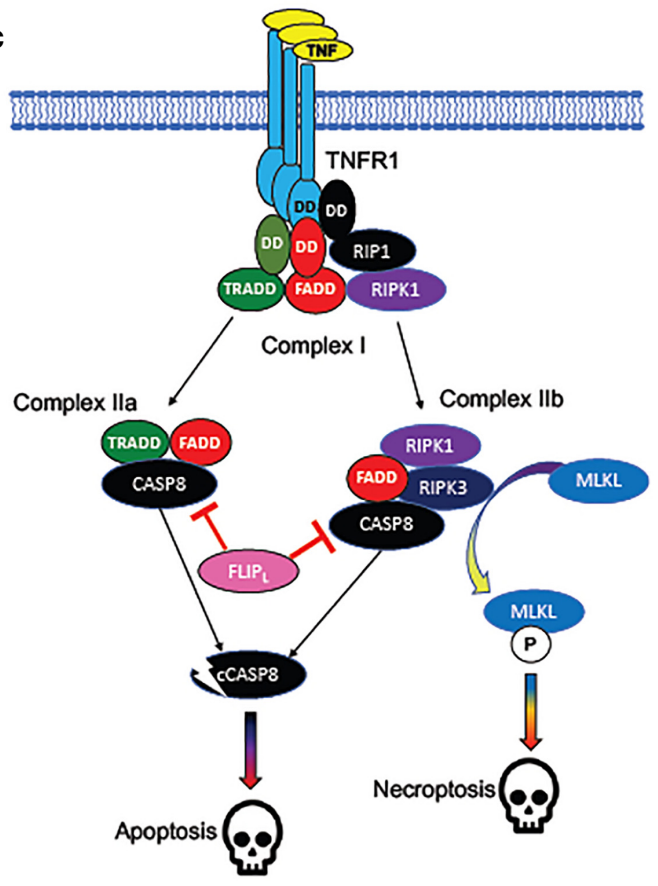

B

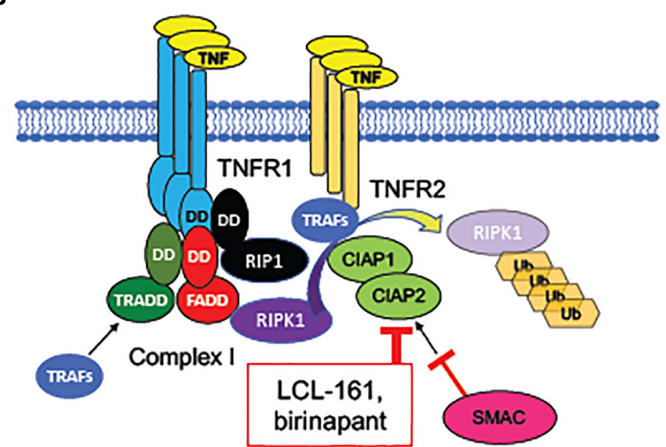

D

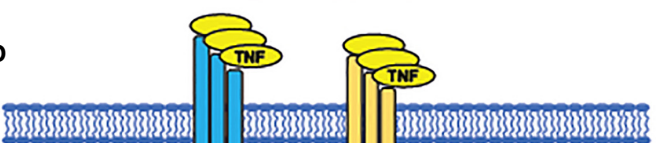

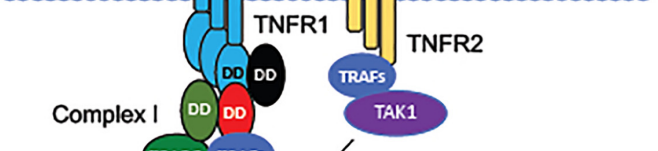

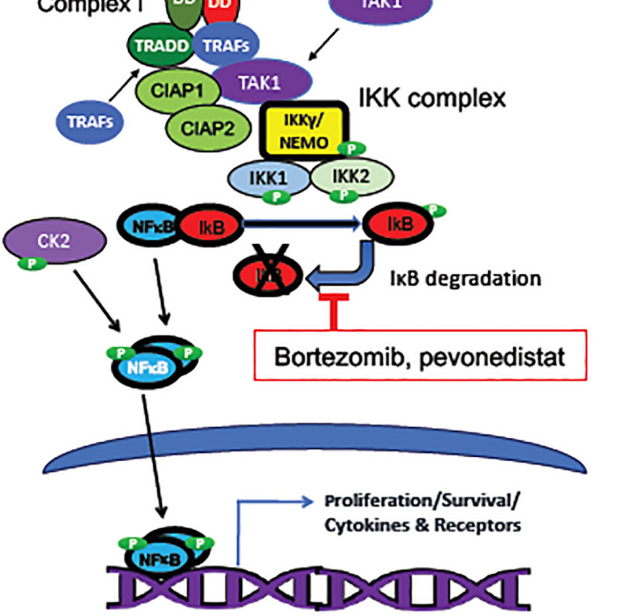

FIGURE 3 | Signaling pathways activated by TNF receptors. (A) Bivalent cell-death regulating Complex I formed at plasma membrane by TNFR1 but not TNFR2. TNF receptors TNFR1 (encoded by TNFSF1A) and TNFR2 (encoded by TNFSF1B) are homotrimeric receptors binding homotrimeric TNF ligand. TNFR1, unlike TNFR2, contains an intracellular "death domain" (DD), which binds homologous DDs on intracellular RIP1, FADD, and TRADD, to compose the core of Complex (I) RIP1 recruits the pro-apoptotic RIPK1 kinase, while TRADD recruits the anti-apoptotic TRAF adaptor protein family members, which are necessary for activation of NFKB and MAP kinase signaling downstream of TNFRs. TNFR2, which lacks a "death domain", can recruit TRAFs directly, but with a lower binding affinity than Complex (I) TRAFs can recruit CIAP1 and CIAP2, anti-apoptotic proteins which form heterodimers (encoded by BIRC2 and BIRC3). (B) Mechanism of cell death inhibition by CIAPs at TNFRs. CIAPs are ubiquitin ligases, which polyubiquinate RIPK1, targeting it for degradation. CIAPs can be recruited intracellularly at TNFbound TNFR1 or TNFR2. SMAC/DIABLO is an inhibitor of CIAPs: hence, SMAC/DIABLO mimetics (such as LCL-161 and birinapant) are pro-apoptotic. (C) Cell death pathways downstream of TNFR1. The uninhibited Complex I (with active RIPK1) promotes formation of the cytoplasmic death promoting Complexes Ila and Illb. Both complexes can activate cytoplasmic CASP8, the cleavage of which, to an active protease (cCASP8), initiates the apoptotic cascade. CASP8 activation can be inhibited by the long form of FLIP, encoded by the NFKB target gene CFLAR: a mechanism by which NFKB activation can promote cell survival. Complex IIb (containing RIPK3 as well as RIPK1) activates the kinase MLKL, which activates the necroptotic signaling cascade. (D) Activation of NFKB by TNFRs. TRAFs bound to TNFR1 or TNFR2 recruit TAK1, an essential activator of NFKB signaling. TAK1 activates the canonical NFKB pathway by recruiting the IKK complex, consisting of NEMO/IKK $\gamma$, IKK1, and IKK2. The IKK complex phosphorylates IKB family members, dissociating them from NFkB subunits and targeting them for degradation. $\mathrm{NFKB}$, freed from $1 \kappa B$, is phosphorylated by both the IKK complex and casein kinase II (CK2), which in tandem activate NFKB subunits, which translocate to the nucleus to act as transcription factors. Bortezomib (directly) and pevonedistat (indirectly) inhibit IkB degradation. Among NFkB target genes are those encoding several cytokines and their receptors, as well as both antiapoptotic and pro-apoptotic components of the TNFR-NFkB signaling cascades.

downstream of Tnfr1 (Figure 3) (100). While neither deletion of Tnfrsfla nor Tnfrsflb alone provided as strong of a rescue as the double knockout, the extent of rescue from Tnfrsfla deletion was much greater than that from Tnfrsf $1 b$ deletion, consistent with
Tnfr1 being the principal Tnf receptor mediating cell death (100).

In contrast to the result reported by Pronk et al. that both Tnf receptors Tnfrsfla and Tnfrsf $1 b$ were required for Tnf-mediated 
repression of normal HSCs in mice (99), Heaton et al. observed that in MF CD34+ cells, selectively inhibiting TNFR2 but not TNFR1 was effective for blocking colony formation (96). In a Jak2 V617F mouse model of MPN, blocking Tnfr2 (Tnfrsf1b) was sufficient to restore the expression of Xiap and Mapk8 that was found to be downregulated in Jak2 mutant vs wild-type cells. These genes were also found downregulated in MF CD34+ cells. These data suggest TNFR2 (TNFRSF1b) is likely to be an important cell-autonomous mediator of clonal expansion $(96,99)$.

Studies have shown that the accrual of secondary mutations, in addition to the primary drivers such as mutations in JAK2, CALR, or $M P L$, can be associated with disease progression and poorer prognosis. Mutations in TET2 are among the most common nonJAK2 mutations occurring in MPNs. Cells from Tet 2 knockout mice and TET2 mutant human HSPCs were observed to have a growth advantage in clonogenic assays over non-mutant control cells (101). Chronic exposure to TNF in these cells led to myeloid skewing and increased resistance to apoptosis (101). A previous study from the same research group showed that macrophages deficient in TET2 were hyperinflammatory (102). Therefore, TET2 mutations, like JAK2 V617F, can lead to similar dual outcomes of promoting both an inflammatory environment and resistance to myelosuppressive effects of TNF, thus leading to clonal dominance of the mutant cells (102). Interestingly, other studies have shown that in MPN patients with JAK2 V617F and TET2 mutations, the presence of the TET2 mutation in single cell-derived clones conferred an advantage towards clonal dominance, but not JAK2 V617F on its own (103, 104). Kent et al. in 2013 studied highly purified JAK2 V617F HSCs from a JAK2 V617F mouse model with an ET phenotype, and observed that the mutation reduced HSC numbers, but that early progenitors exhibited increased proliferation and differentiation (105). This result suggests that while JAK2 V617F confers hyperproliferation to the malignant clone within the myeloid progenitor population, it may be insufficient to establish clonal dominance at the level of HSC, and therefore that additional mutations or other pathogenic mechanisms may be necessary for clonal dominance to occur within the HSC population.

\section{NFKB PATHWAY HYPERACTIVATION IS SYSTEMIC IN MPNS AND MAY AFFECT STROMAL-HEMATOPOIETIC INTERACTIONS}

$\mathrm{NF \kappa B}$ signaling hyperactivation has been observed in multiple cancers, including lymphoid neoplasms (106), AML (107), MDS (108), and myelofibrosis (109). In contrast to lymphoid neoplasms, where mutations in $\mathrm{NFKB}$ pathway related genes are common, in myeloid neoplasms, mutations in NFKB pathway related genes are very rare (110). Since NFKB signaling is not (or very rarely) altered directly by mutation in myeloid neoplasms, it must be altered indirectly.

The indirect constitutive activation of NFאB signaling (i.e. not via mutation of an integral $\mathrm{NF \kappa B}$ pathway component) may occur by a combination of cell-autonomous and non-cellautonomous mechanisms (Figure 4). NFKB signaling can be activated cell-autonomously by signaling downstream of an activating kinase mutation, such as FLT3-ITD or JAK2 V617F. A mechanism has been described for FLT3 to activate NFKB signaling by direct binding to the IKK complex and consequent phosphorylation of IKK2 (114). A similar mechanism has been described where a Ras/PI3K/AKT pathway activated in AML cells led to activation of NFKB, which could be suppressed by pharmacologic AKT inhibition (111). Since the PI3K/AKT pathway, as well as NFKB, can be activated by TNF (97), this could be considered a feed-forward activation downstream of TNF receptors. Activation of ERK and downstream targets have been identified in individual MF and post-MPN sAML patients (33), and likewise JAK2-dependent ERK activity has been shown to contribute to disease phenotypes in JAK2 V617F and MPL W515L expressing mice (112). The cell cycle activating kinase CDK6 is another potential activator of NFKB, as it shares with

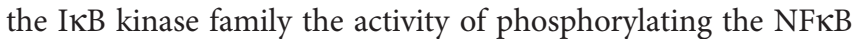
subunit p65/RELA at serine 536, a phosphorylation necessary for activating it as a transcription factor $(113,115,116)$. This would suggest the possibility that myeloproliferative HSPC could have higher intrinsic NFKB activity than quiescent HSPC, simply by virtue of higher CDK6 activity present in the cell cycle. In MPNs, this would presumably be an indirect consequence of the JAK2 hyperactivity responsible for the myeloproliferative phenotype. The role of CDK6 in MPNs is currently unclear: mice with Cdk6 deletion along with JAK2 V617F exhibited a somewhat less severe MPN phenotype than mice with $J A K 2$ V617F alone, but observed effects on $\mathrm{NF \kappa B}$ target gene expression were ambiguous (117).

A prevalent alternative hypothesis is that in myeloid neoplasms, and particularly in MPNs, NFKB signaling is most often activated non-cell-autonomously by inflammatory mediators. The most prominent suspects include the known $\mathrm{NF} \kappa \mathrm{B}$ activating ligands IL- $1 \alpha$ and $\beta$, which have been shown to be upregulated in some cases of AML (118) and MF (43)(note that circulating levels of IL-1 are normally undetectable), and which can promote myeloproliferation and HSC depletion in mice (119); endogenous toll-like-receptor (TLR) ligands, such as S100A8 and S100A9, which are overexpressed in MF CD34+ cells $(48,77)$; and, most of all, TNF, which is frequently overproduced in all chronic MPNs (53), as well as in a subset of AMLs, most often corresponding to the M4/M5 (myelomonocytic) FAB subclass (82). While circulating TNF is normally undetectable in healthy individuals (43), it is detectable in the plasma of almost all MF patients, and of many PV, ET, and sAML patients $(33,41,48,53)$. Likewise, while it is not yet clear what proportion of patients with any category of myeloid neoplasm feature NFKB signaling hyperactivation, our study using mass cytometry identified that, in CD34+ cells from the majority of MF patients studied, levels of phosphorylated, and hence active, NFkB subunit p65/Rela, were above the range observed in healthy controls (33).

$\mathrm{NF \kappa B}$ signaling hyperactivation observed in $\mathrm{MF}$ and in sAML, however, was not confined to CD34+ cells, but rather 
A

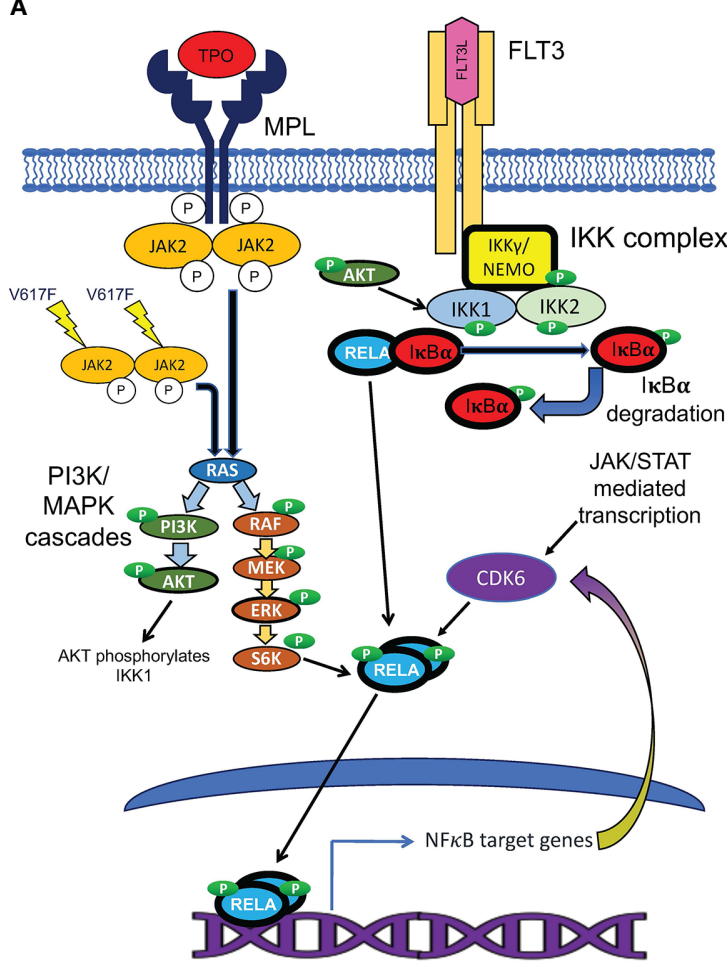

B

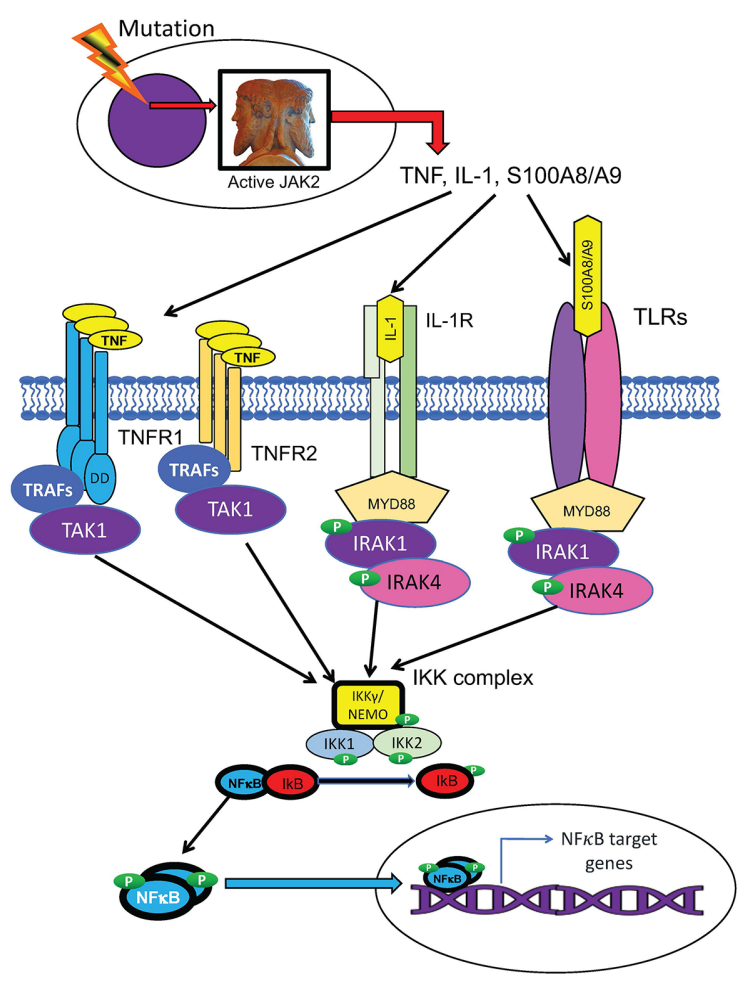

FIGURE 4 | Cell-autonomous and non-cell-autonomous paths to NFKB pathway activation in MPNs. (A) Hypothesized pathways for cell-autonomous activation of NFKB downstream of active JAK2. JAK2 is activated by cytokine receptors such as MPL, or constitutively resulting from the V617F mutation. Active JAK2 activates RAS, in turn activating the MAP kinase and PI3 kinase signaling cascades, which are active in MPN HSPCs. Reported inputs of these pathways to NFKB include phosphorylation of IKK1 by AKT and phosphorylation of p65/RELA by S6 kinase (111, 112). The cell cycle kinase CDK6, a transcriptional target of both JAK/STAT and NFKB signaling, also can phosphorylate RELA (113). Active phosphorylated RELA translocates to the nucleus to mediate transcription. (B) Several non-cellautonomous inputs overproduced in MPNs can activate NFKB. MPN driver mutations produce JAK2 hyperactivity, which leads to pathophysiologic production of TNF, IL-1, and TLR ligands S100A8/A9 and related family members. NFKB is activated either by TNFRs via TRAFs and TAK1, or by TLRs or IL-1 receptor, via the adaptor protein MYD88, which binds to these receptors, and recruits IRAK1/IRAK4 kinase heterodimers, which in turn activate the IKK complex.

was observed throughout both myeloid and lymphoid cell populations (33). This is consistent with a non-cellautonomous etiology. In a study using mouse transplant models of MPNs with activated alleles of either JAK2 or MPL, co-transplanted with wild-type mouse bone marrow cells, NFKB hyperactivation was observed in co-transplanted non-mutant hematopoietic cells as well as mutant cells $(84,86)$. Likewise in human MPNs, the total population of lymphoid cells is most frequently only partly derived from the malignant clone, as malignant hematopoiesis is typically myeloid-biased (78). The prevalent hypothesis is, therefore, that NFKB hyperactivation is transmitted from the malignant clone to the residual nonmalignant hematopoietic cells and to bone marrow and splenic stroma via NFKB-activating cytokines.

Our group's study of cytokine production by mass cytometry identified overproduction of several cytokines in MF monocytes and myeloid progenitor cells, which derive heavily from the malignant clone in most MF patients (78). Frequently overproduced cytokines in MF monocytes and myeloid progenitors included TNF and the ex vivo TNF-inducible cytokines IL-6, IL-8/CXCL8, CCL4/MIP-1 $\beta$, and IL-1RA (48). This exact set of cytokines was previously shown to be overproduced in MF granulocytes (86). Likewise, these cytokines were among the larger set previously observed to be elevated in MF patient plasma (43). These cytokines represent a credible means for the malignant clone to induce NFKB hyperactivation and other signaling effects in the residual nonmalignant hematopoietic and stromal cells (Figure 5).

Mouse homologs of MF-overproduced cytokines (except for IL-8/CXCL8, which does not have a direct homolog in mice) are overproduced in JAK2 V617F (or Jak2 V617F, if the mouse gene was mutated rather than the mutant human gene introduced) and MPL W515L MPN mouse models, and furthermore are also overproduced in non-mutant mouse cells co-transplanted with $J A K 2$ or MPL mutant cells: a non-cell-autonomous induction directed by the malignant cells, in direct analogy to human MPNs (86). Cytokine overproduction in MPN model mice was found to be heavily dependent on Jak2 phosphorylation of Stat3 (86), and on a maintenance of elevated NFKB-dependent gene expression by BET bromodomain proteins (84). In these studies, 
A

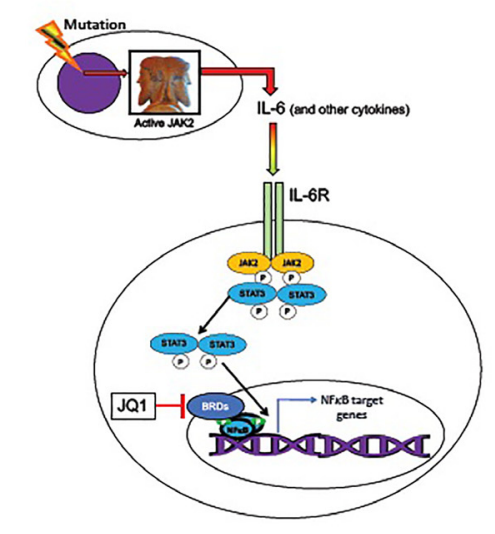

C

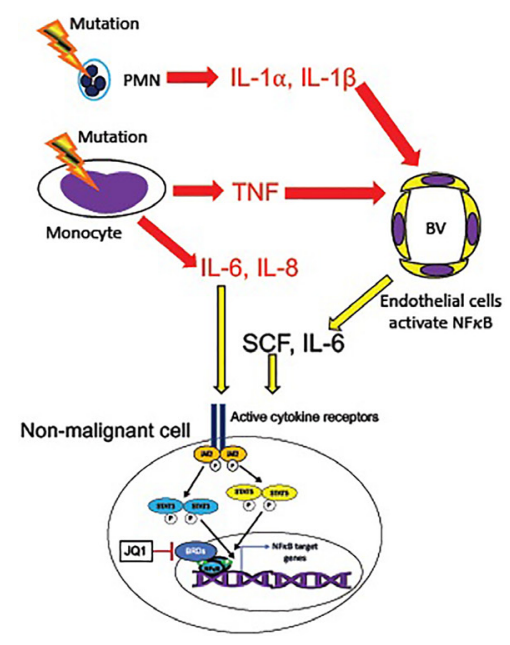

B

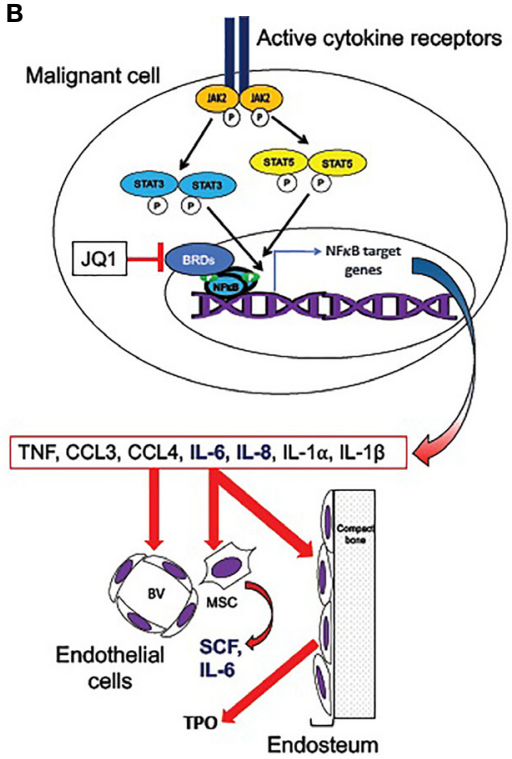

FIGURE 5 | Transmission of JAK/STAT and NFKB pathway activation from malignant to non-malignant cells. (A) Malignant hematopoietic MPN cells transmit NFkB signaling activation to non-malignant cells, according to the hypothesized mechanism described by Kleppe et al. (86) MPN driver mutations produce hyperactive JAK2, leading to overproduction of cytokines, including IL-6. IL-6 receptor activation (in non-malignant cells) activates JAK2 and STAT3, which are required for maximal non-cell-autonomous NFKB activation in non-malignant cells. STAT3 shares multiple target genes with NFkB. NFkB mediated transcription requires BET bromeodomain proteins (BRDs) as cofactors, and therefore is subject to inhibition by the BRD inhibitor JQ1. (B) Active cytokine receptor signaling (such as from MPL or IL-6R) in malignant cells activates JAK2 and phospho-STATs 3 and 5, which co-activate multiple target genes along with NFKB. Among JAK2/STAT3,5 and NFkB co-induced targets are genes encoding several cytokines overproduced in MPNs: TNF, CCL3 (MIP-1 $\alpha$ ), CCL4 (MIP-1 $\beta$ ), IL-6, IL-8, IL-1 $\alpha$, and IL-1 $\beta$ (41, 48, $53,84,86)$. IL-6 and IL-8 (bold) can activate JAK2/STAT3,5 signaling in non-mutant cells. These cytokines in turn act non-cell-autonomously on the endothelial cells of blood vessels (BV), mesenchymal stromal cells (MSC), and endosteal cells in the bone marrow. MSC are sources of SCF and IL-6 and endosteal cells are sources of TPO, which can activate JAK2/STAT3,5 signaling non-cell-autonomously (also see Figure 6). (C) Malignant neutrophils (PMN) in MPNs can produce IL-1 $\alpha$, and IL-1 $\beta$, while malignant monocytes produce IL-6, IL-8, and TNF. TNF, IL-1 $\alpha$, and IL-1 $\beta$, can activate NFKB signaling in endothelial cells of blood vessels (BV), leading them to release SCF and IL-6. These cytokines can combine with IL-6 and IL-8 secreted by malignant monocytes to produce activated JAK2/STAT3,5 signaling in both malignant and non-malignant cells.

bone marrow fibrosis was also reduced by either Stat3 deletion (86) or treatment with BET bromeodomain protein inhibitor JQ1 (84). Notably, the dependence of cytokine overproduction on Stat3 was only observed when all transplanted donor cells were Stat 3 null. In a co-transplant experiment with MPL W515L, Stat 3 -/- cells co-transplanted with wild-type mouse cells, cytokines were produced at levels similar to MPL W515L transplant recipients with intact Stat3 (86). Therefore, the requirement of Stat3 for cytokine production was found in non-malignant cells, in which cytokine production was induced non-cell-autonomously by the malignant cell population (Figure 5).

Much as the malignant clone can induce activation of NFKB signaling, and hence cytokine overproduction, even in residual non-malignant hematopoietic cells, it can also do the same to the non-hematopoietic stromal compartments of the bone marrow. Bone marrow stroma is a unique environment that supports normal hematopoiesis, known as the hematopoietic niche, which is severely disrupted by malignant hematopoiesis, particularly in MF and AML (120-123). In healthy bone marrow, HSCs are 
mainly localized to two distinct niches: the endosteal niche, characterized by direct HSC-osteoblast contact, and containing primarily quiescent HSCs; and the perivascular niche, characterized by direct contact of HSCs with endothelial cells, and containing the majority of proliferating, and potentially mobilized, HSCs and HSPCs (Figure 6). These niches both feature direct contact of HSCs and HSPCs with CXCL12abundant reticular cells (CAR cells), which maintain HSPC localization in the bone marrow by producing CXCL12, which activates the receptor CXCR4 on HSPCs. Disruption of HSPCCAR cell contact in MF may be one of the causes of the HSPC mobilization typically observed in MF. Mesenchymal stromal cells of the bone marrow (of which CAR cells are a subpopulation) are hypothesized to be the major fibrogenic cells in MF (124), although a role has also been described for monocyte-derived fibrocytes (71). Unquestionably, malignant hematopoietic cells can induce pathophysiologic changes in the non-malignant cells of the hematopoietic niche, via released cytokines and cell-contact-mediated factors.

Pathophysiologic intracellular signaling alterations in hematopoietic niche cells almost certainly produce reciprocal paracrine effects with malignant and non-malignant hematopoietic cells (Figures 5 and 6). Mesenchymal stromal cells in the bone marrow are a source for HSPC-promoting cytokines, including stem cell factor (SCF) and IL-6, and osteoblasts are a source for TPO, which promotes HSC quiescence in the endosteal niche $(125,126)$. NFKB activation in hematopoietic niche cells is likely to severely affect hematopoiesis. This hypothesis is supported by a recent study which used an inducible endothelial-specific expression system to produce constitutive MAP kinase signaling in endothelial cells, downstream of an introduced phosphorylation-mimic
A

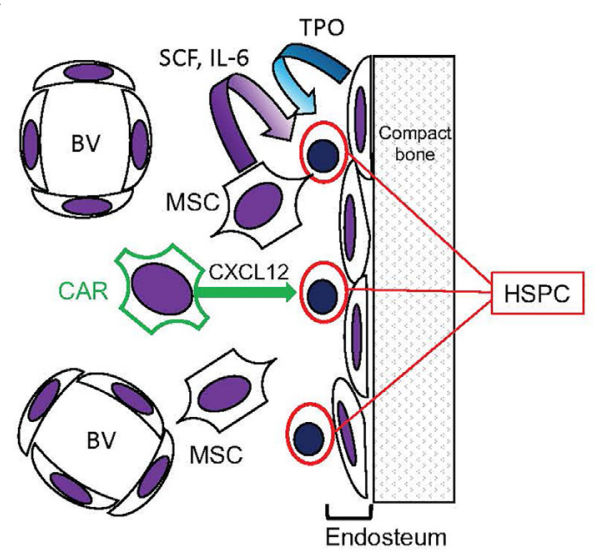

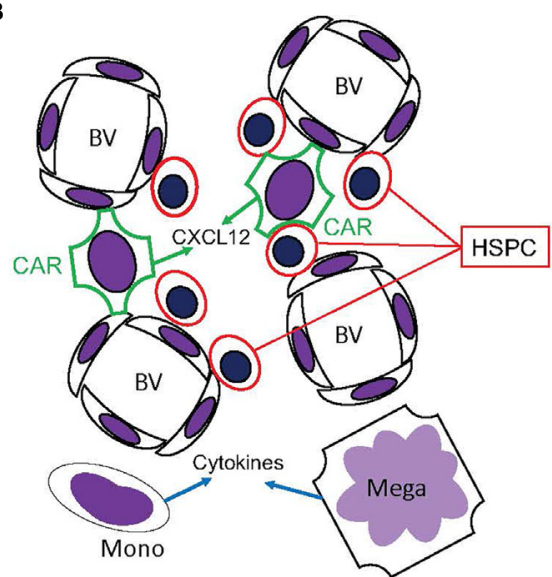

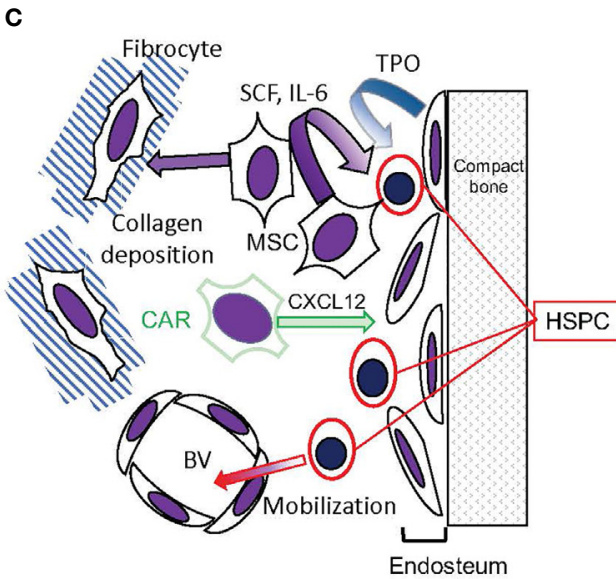

D

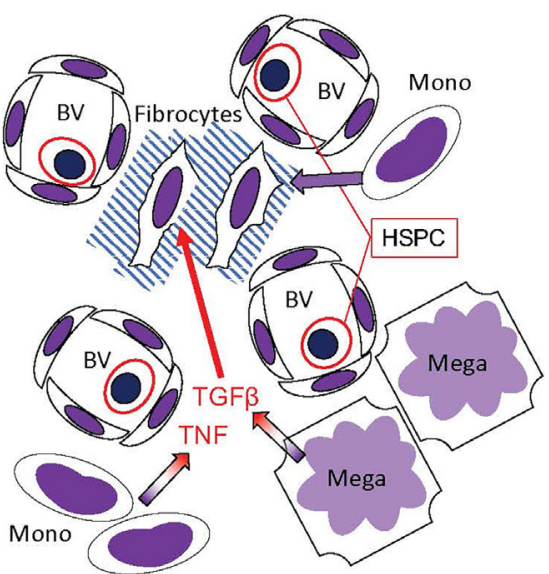

FIGURE 6 | Hematopoietic bone marrow niches disrupted in MPNs. (A, B) Bone marrow niches in healthy hematopoiesis. (A) The endosteal niche: HSPC reside in contact with the endosteum, composed of osteoblasts that release TPO, promoting HSC quiescence. CXCL12 secreted by CAR cells promotes HSPC stasis in the bone marrow, while mesenchymal stromal cells (MSC) secrete SCF and IL-6. (B) The perivascular niche: HSPC reside in contact with blood vessels (BV), which are also contacted by the CXCL12-secreting CAR cells. This niche, however, is more prone to HSPC circulation than the endosteal niche. Monocytes (Mono) and megakaryocytes (Mega) secrete cytokines active on HSPC. (C, D) Disruption of hematopoietic niches in MF. (C) In MF, MSCs are abundant but CAR cells are reduced. The endosteum can be disrupted, and MSCs can differentiate into fibrocytes and deposit collagen, disrupting blood vessels in the hematopoietic space. Consequently, HSPC become mobilized. (D) Monocytes and megakaryocytes become abundant in the MPN bone marrow, releasing cytokines including TNF and the fibrogenic TGF $\beta$. Monocytes, as well as MSCs, can differentiate into fibrocytes (71). 
MAPKK1 S218D, S222D (127). This produced secondary NFאB signaling hyperactivation in the bone marrow endothelial cells (plausibly a cell-autonomous effect), and the hematopoietic phenotype of HSC depletion by induction of proliferation and differentiation of HSC to myeloid progenitors, and consequent preferential production of myeloid cells in the setting of overall pancytopenia (Figure 7A). This hematopoietic phenotype very closely resembles phenotypes observed when a phosphorylationmimic Ikk2 (IKBKB) S177E, S181E was expressed panhematopoietically in mice, either heterozygously (129) or homozygously (130). It also resembles mouse phenotypes obtained when A20/TNFAIP3, an inhibitor of NFKB signaling activation by activated TNFR1, TLRs, and other signaling receptors, was eliminated (131-134). Furthermore, the

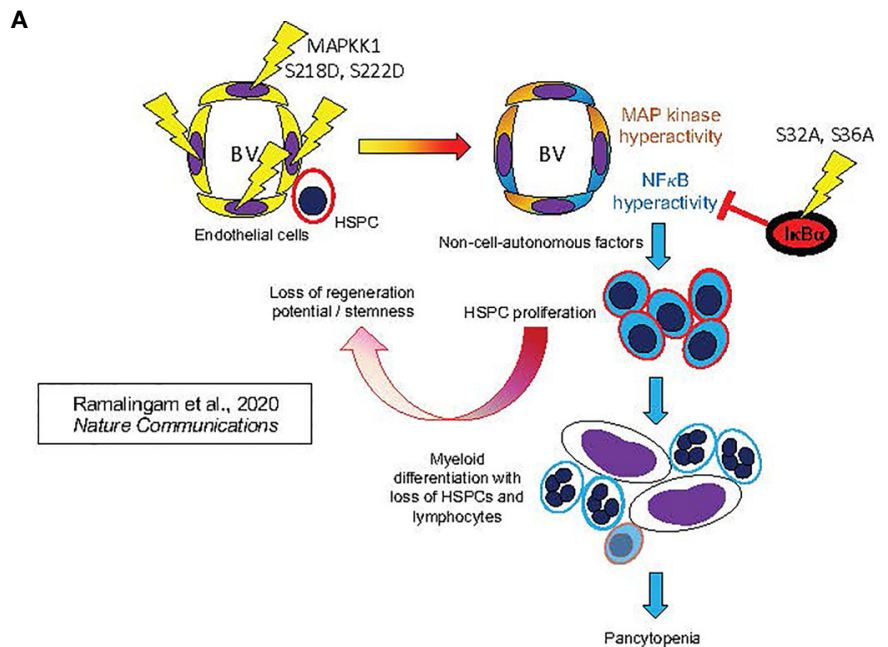

B 1. Healthy bone marrow

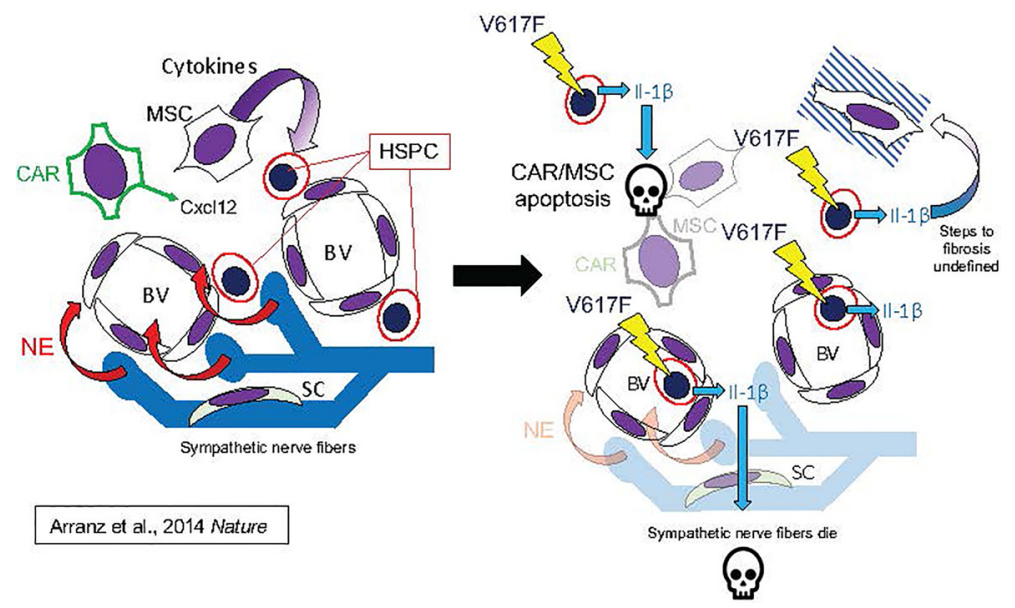

FIGURE 7 | Hypothesized mechanisms of bone marrow niche remodeling in MPNs based on studies in mouse models. This figure illustrates mechanisms hypothesized from mouse model studies by Ramalingam et al. (127) Nature Communications (127) (A) and by Arranz et al. (128) Nature (128) (B). (A) (from top left, following arrows indicating course of pathogenesis): Expression of MAPKK1 S218D, S22D mutant in endothelial cells, resulting in constitutive activation of MAP kinase signaling, also produced constitutive NFKB activation, possibly by a cell-autonomous mechanism, as described in Figure 4A. This led to HSPC proliferation and losses of stemness and regeneration potential in mouse HSPC: phenotypes derived non-cell-autonomously, since mutant MAPKK1 expression was confined to endothelial cells. HSPC phenotypes were dependent on NFKB hyperactivation in HSPC, as they could be entirely rescued by hematopoietic expression of the non-

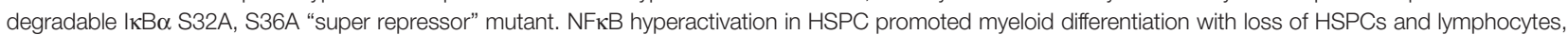
resulting in pancytopenia and bone marrow failure (a phenotype also observed to result from pan-hematopoietic NFkB hyperactivation in mice) (129-133). (B) Bone marrow remodeling by hematopoietic Jak2 V617F, analogous to human MPNs. 1. In healthy mouse bone marrow, Cxcl12 secreted by CAR cells and cytokines secreted by MSCs maintain HSPCs in the perivascular niche (analogous to Figure 6B). Bone marrow also contains sympathetic nerve fibers, which secrete norepinephrine (NE). Schwann cells (SC) are associated with the sympathetic neuronal fibers, and essential for their survival. 2. Jak2 V617F, expressed in hematopoietic cells, causes secretion of $\|-1 \beta$ (II-1 $\alpha$ was not assayed). II-1 $\beta$ caused apoptosis of CAR cells, other MSCs, and Schwann cells, leading to sympathetic denervation of bone marrow. The exact downstream signaling pathways to apoptosis and marrow fibrosis were not defined in this study. These features were, however, substantially rescued by either a catecholaminergic agonist or the natural $\|-1$ receptor antagonist $\|-1$ ra, establishing essential roles of both $\|-1$ and sympathetic denervation in bone marrow pathophysiology caused by Jak2 V617F. 
hematopoietic phenotype induced by endothelial MAP kinase pathway hyperactivation was completely suppressed by introduction of IKB $\alpha$ (NFKBIA) S32A, S36A "super repressor", which constitutively inhibits canonical NFKB signaling, exclusively in the endothelial cells (127). The implication is that NFKB hyperactivation in bone marrow endothelial cells, derived secondarily to MAP kinase pathway hyperactivation, was transmitted non-cell-autonomously to the hematopoietic compartment, resulting in NFKB-hyperactivated hematopoiesis. A reverse of this process may occur in MPNs, where NFאB signaling hyperactivation in hematopoietic cells can produce cytokine-mediated circular positive feedback with signaling hyperactivation in endothelial or mesenchymal components of the hematopoietic niche. Notably, inhibition of NFKB in mouse endothelial cells was also observed to improve hematopoietic recovery after myeloablative insults (135). This is further supporting evidence that inhibiting NFKB signaling may be a useful therapeutic modality to promote recovery of residual benign hematopoiesis.

Hematopoietic niche remodeling produced by JAK2 V617F has also been modeled in mice (Figure 7B). An inducible JAK2 V617F mouse model (using Mx1-Cre, induced by poly-inosinecytidine, a.k.a. poly-IC or PIPC) exhibited apoptosis of nestinexpressing mesenchymal stem cells (MSCs) and Schwann cells of sympathetic nerve fibers within the bone marrow, and consequent loss of sympathetic innervation (128). These pathophysiologic changes could be substantially prevented by 16-week treatment with either a catecholaminergic agonist or Il$1 \mathrm{ra}$, an endogenous antagonist of Il-1 receptor, the human homolog of which, along with IL- $1 \alpha$ and $\beta$, is also overproduced in human MF $(43,48)$. In the mouse model, the sequence of pathogenic events appeared to be: (1) secretion of Il$1 \beta$ from hematopoietic cells (Il-1 $\alpha$ was not assayed), (2) loss of catecholaminergic nerve fibers, (3) loss of Cxcl12 expression in mesenchymal stromal cells, resulting in (4) mobilization of HSPCs from bone marrow, and finally (5) apoptosis of mesenchymal stromal cells (128). It is notable not only that a chain reaction of pathogenic events was unleashed non-cellautonomously by JAK2 V617F, but also that the second step in the chain, after JAK2 hyperactivation, was release of Il-1 $\beta$, an $\mathrm{NF} \kappa \mathrm{B}$ activating ligand, from the hematopoietic cells. Therefore, an important role of $\mathrm{NF \kappa B}$ in the remodeling of the bone marrow niche by MPNs is probable.

$\mathrm{NF} \kappa \mathrm{B}$ signaling in HSPCs is thought to be a mediator of "stress hematopoiesis", or "emergency hematopoiesis", in which HSPCs are activated to produce granulocytes, erythrocytes, and megakaryocytes, in the setting of sepsis or another extreme hematopoietic insult (92). MPNs can be considered to hijack the normal mechanisms of stress hematopoiesis to remodel the bone marrow niche in a manner deleterious to benign hematopoiesis, but to which the malignant clone is adaptable, and through which it thrives.

It is relevant to note that while NFKB signaling is clearly implicit in the pathophysiology of MPNs, its effects other than induction of cytokine production remain largely unknown. Moreover, not all $\mathrm{NFKB}$ signaling is equal in the context of myeloid neoplasms. NFKB can be activated by two major upstream signaling pathways, termed canonical and noncanonical NFKB signaling (115). It was found that a stabilized, non-degradable mutant of NFKB-inducing kinase (NIK), a crucial mediator of non-canonical NFKB signaling, prolonged survival of MLL-AF9 AML mouse transplant recipients (136). The effects of this mutation included a severe downregulation of nuclear Rela, a canonical NFkB subunit, which is elevated in and essential for MLL-AF9 AML (137), as well as upregulation of nuclear non-canonical NFאB subunits Relb, p50, and p52 (136). This is consistent with previous findings that canonical and noncanonical NFKB subunits can inhibit, as well as activate, transcription, depending on the exact DNA target sequence bound (115), and that Rela and Relb can mutually antagonize by the formation of inactive heterodimers (138). In MF CD34+ cells, while NFKB target genes were predominantly expressed at higher levels than in normal control CD34+ cells, a subset of NFKB-related genes, including REL and NFKB1, were observed to be downregulated in MF versus control CD34+ cells, suggesting a dichotomy in the pathologic dysregulation of NFKB signaling (33). This dichotomy, however, was not straightforwardly explicable as a divergence of canonical versus non-canonical NFKB signaling $(33,115)$.

\section{JAK INHIBITOR BENEFITS AND LIMITATIONS MAY RELATE TO CYTOKINE MEDIATED INFLAMMATION}

JAK inhibitors have demonstrated efficacy in reducing spleen volume and improving constitutional symptoms associated with MPNs, but the only curative therapy remains allogeneic stem cell transplant. Indeed, amelioration of splenomegaly was one of the principal aims targeted in the COMFORT trials of ruxolitinib for treatment of MF (139, 140). Ruxolitinib has been shown to reduce elevated levels of circulating inflammatory cytokines in MF, which may underlie the improvement in constitutional symptoms and splenomegaly observed with treatment (57). While ruxolitinib improves symptoms, it does not eradicate the malignant clone, induce molecular remission, or prevent transformation to acute myeloid leukemia (AML), and only shows modest survival benefit. Studies conducted in our laboratory indicated that ruxolitinib therapy reduces but does not rectify cytokine overproduction in MF (48). These findings may explain why certain disease features such as malignant clonal burden and marrow fibrosis remain refractory to ruxolitinib therapy.

Other JAK inhibitors besides ruxolitinib, namely momelotinib, pacritinib, and fedratinib, have demonstrated some ability to reduce cytokines overproduced in MF beyond that observed with ruxolitinib, possibly due to their inhibitory actions on other signaling molecules besides JAK2 (70, 141-145). Notably, both ruxolitinib and momelotinib inhibit JAK1 as well as JAK2, while pacritinib and fedratinib are relatively more specific for JAK2. JAK1 is activated by interferons, IL-3, IL-7, 
IL-6 and related cytokines, and IL-2 $(86,146)$. This means it could play a significant role in inflammatory responses to cytokines induced in MPNs. JAK1 overlaps with JAK2 in phosphorylating STAT3, which is necessary for signaling activated by multiple cytokines, and Stat 3 is necessary for maximal cytokine production in MPL W515L model mice (86, 146). Loss of Jakl in mouse hematopoiesis causes accumulation of HSPCs, and blunted or absent proliferative responses to Il-3, Il-6, and type I interferons (84). Therefore, inhibition of JAK1 could potentially reduce both myeloproliferation and cytokinemediated pathophysiology in MPN patients. Itacitinib, a JAK1 specific inhibitor, was studied in a Phase 2 trial of MF patients (142). Itacitinib produced reductions of constitutional symptoms and splenomegaly, but only modest or inconsistent reductions in plasma cytokines, or cytokines produced in MF myeloid cells ex vivo $(48,142)$.

Other relevant non-JAK targets of JAK inhibitors include FLT3 and Interleukin Receptor Associated Kinase-1 (IRAK1), targeted by fedratinib and pacritinib; JNK (also known as MAPK8 or SAPK1), targeted by momelotinib; and CSF1R, also targeted by pacritinib. IRAK1 is a Ser/Thr kinase activated downstream of IL-1 receptor and TLRs (see Figure 4). Active IRAK1 dimerizes with TRAF6 to activate the IKK complex, and hence, $\mathrm{NFKB}$ signaling. Implicitly, IRAK1 inhibition might reduce $\mathrm{NF \kappa B}$ signaling in the presence the ligands of IL-1 receptor and TLRs. Likewise, CSF1R inhibition might mitigate monocytosis. IRAK1 inhibition has been proposed as a therapeutic strategy for myelodysplastic syndromes (MDS), as well as MPNs, based on preclinical studies (147). JNK/MAPK8 is a kinase that can be activated by TNF separately from NFKB signaling. It activates the AP-1 transcription factor, which shares a number of anti-apoptotic target genes with NFKB. Volk et al. (97) found that co-inhibition of JNK and NFKB signaling in $M L L-A F 9$ induced mouse model leukemic blasts could induce cell death (primarily necroptosis) in the presence of Tnf (97). Therefore, effects on several of the known targets of JAK inhibitors other than JAK2 could provide therapeutically useful effects.

Like ruxolitinib, other JAK2 inhibitors have also not demonstrated an impact on malignant clonal burden or reduction in bone marrow fibrosis. Ultimately, the consequences of cytokine overproduction in MF disease pathogenesis and the cellular pathways involved require further exploration in order to improve therapy for MPNs.

\section{INFLAMMATORY SIGNALING IS A BASIS FOR NOVEL MPN TREATMENT MODALITIES}

The clearly prominent role of inflammation in the pathophysiology of MPNs has led to the hope that inflammatory signaling, either between or within cells, could be manipulated to lead to improved options for treatment. Prior studies have suggested links between TNF and clonal expansion,
TGF $\beta$ and fibrosis, and IL-1 ( $\alpha$ or $\beta$ ) and pre-fibrotic damage to the bone marrow milieu $(53,128,148)$. The fibrogenic effect of TGF $\beta$ is likely to be separate from the pathogenesis of clonal expansion and myeloproliferation. A study using the JAK2 V617F transgenic and MPL W515L retroviral transplant mouse models of MF showed improvement of bone marrow fibrosis and splenomegaly with galunisertib, an antagonist of the TGF $\beta$ receptor serine/threonine kinase ALK5, despite absence of any effect on any other hematologic parameter (148). Therefore, antifibrotic treatments, especially if targeting TGF $\beta$ or its downstream signaling, will likely need to be combined with anti-myeloproliferative agents such as ruxolitinib (149, 150), and/or agents for reducing malignant clonal burden, such as IFN $\alpha$.

Alternate approaches for MF treatment could include targeting inflammatory signaling in the pre-fibrotic alterations of the bone marrow milieu or manipulating the inflammatory signaling abnormalities present in the disease to trigger cell death in the malignant clone. This latter approach is suggested by the known signaling pathways activated by the cytokine TNF (Figure 3). While TNF is an activating ligand for NFKB, MAP kinase, and JNK signaling, it also can activate a variety of cell death modalities: these are activated by a death-promoting signaling cytoplasmic complex known as Complex II (as opposed to the bivalent TNFR1 signaling Complex I), which is activated specifically by TNF binding to its receptor TNFR1 (TNFRSF1A), but not by the alternate TNF receptor TNFR2 (TNFRSF1B) (81). TNFR1, TNFR2, and members of the TLR/IL1 receptor superfamily can all activate $\mathrm{NF \kappa B}$ signaling, but only TNFR1 and several of its relatives, such as FAS/CD95, can activate Complexes I-II, which in turn activate signaling that can lead to apoptosis, necroptosis, or pyroptosis $(81,151)$. NFKB is known to activate transcription of a number of known antiapoptotic target genes, including BCL2 and CFLAR (encoding cFLIP) (152). Therefore, it is hypothesized that inhibiting NFKB in the presence of TNF might promote cell death mediated by TNFR1 and Complexes I-II.

Etanercept, a dimeric recombinant TNFR2 (TNFRSF1B) extracellular domain fusion protein with human IgG1-Fc, is used clinically along with other TNF/TNFR antagonists as an anti-inflammatory agent, and was used as a single agent in a clinical trial for MF, resulting in improvement of constitutional symptoms, somewhat similar to observed effects of ruxolitinib (153). TNF/TNFR antagonism, however, does not exploit the principle of antagonizing anti-apoptotic effects of inflammatory signaling, while maintaining cell death inducing signaling intact.

Several basic studies in mice and human cells support a rationale for targeting NFKB activation downstream of TNFRs, with the goal of killing malignant HSPCs. Acute Tnf treatment in normal mice was observed to induce rapid cell death in the bone marrow, to which normal HSCs and Cd41+ megakaryoblasts were almost entirely resistant (with other primitive myeloid progenitors being partially resistant, in comparison with granulocytes), with these resistant populations being induced to enter the cell cycle, rather than being killed (95). The preservation of HSC was found to be dependent on the NFKB 
subunits p50 and p65/Rela, in absence of which HSC would succumb to a combination of apoptosis and necroptosis (Figure 3). This was coincident with more abundant nuclear p50 and p65/Rela in HSC than in other cells, and higher ratios of Tnfr2 to Tnfr1. Furthermore, human gene homologs of mouse HSC and GMP Tnf-induced gene expression signatures were found to be upregulated in human aging, MDS, and AML (95). Similarly, human MF but not healthy control CD34+ HSPC were found to be sensitive to reduction of colony forming activity by a TNFR2 (TNFRSF1B) blocking antibody, coincident with elevated expression of anti-apoptotic BIRC2 and BIRC3 (encoding cIAP1/2), and reduced expression of pro-apoptotic $X I A P$ and MAPK8 (encoding JNK), in MF HSPC (96). These results are similar to those of a study showing that combined inhibition of NFKB and JNK could promote apoptosis and necroptosis in AML blasts (97); although the role of JNK observed in the MF and AML studies was opposite $(96,97)$. Put together, the results of these studies suggest that HSCs, and MF HSCs in particular, may be dependent on TNFR2 signaling to $\mathrm{NF \kappa B}$, to rescue them from cell death, which would otherwise be induced by TNF through TNFR1.

Canonical NFKB signaling, in absence of an activating signal, is inhibited in the cytoplasm by the endogenous inhibitor $\operatorname{I\kappa B} \alpha$, and signal activation by TNF triggers the degradation of $I \kappa \mathrm{B} \alpha$ (Figure 3D). Given this knowledge, therapeutic agents that could prevent the degradation of I $\mathrm{K} B \alpha$ have been considered potential therapeutic NFKB inhibitors, including in the treatment of myeloid neoplasms. Bortezomib, a proteasome inhibitor with clinical activity against multiple myeloma, was able to inhibit both NFKB activation and bone marrow fibrosis in mice treated with Tpo (154). Phase I/II clinical trials of bortezomib for MF, however, showed no clinical benefit and significant toxicity (155, 156). There is no evidence currently suggesting specificity of bortezomib for $\mathrm{I} \kappa \mathrm{B} \alpha$.

A logically equivalent approach has been undertaken with another indirect NFKB inhibitor, pevonedistat, which inhibits the neddylating enzyme NAE, responsible for a covalent modification to cullin ring ligase enzymes necessary for the degradation of $\mathrm{I} \kappa \mathrm{B} \alpha$ (157-160). Pevonedistat has been shown to synergize with TNF in promoting apoptosis of hepatoma cells (157), and has observed proapoptotic activity against AML, MDS, ALL, and lymphoma cells (158, 160-164). Pro-apoptotic effects of pevonedistat may be enhanced in combined treatment with other pro-apoptotic agents, such as BCL-2 antagonists or SMAC (second mitochondria-derived activator of caspase, also known as DIABLO) mimetics (162), or in combination with HDAC inhibitors (159). HDAC inhibitors, which can actually enhance NFKB activity by preventing deacetylation of p65/RELA, can provide apoptosis in combination with NFKB inhibition $(165,166)$.

We have also observed pevonedistat to inhibit production of TPO/TLR/TNF-inducible cytokines from MF patient myeloid cells ex vivo, supporting its potential as an anti-inflammatory agent for MF (48). Based on this hypothesis, our group has initiated a Phase I clinical trial, combining pevonedistat with ruxolitinib for MF treatment (NCT03386214). Phase I/II studies of pevonedistat in MDS and AML have shown tolerability, and a
Phase III study of pevonedistat in combination with azacitidine in MDS/AML is currently ongoing (NCT03268954) (167-169). A caveat with pevonedistat is that, like bortezomib, its activity may not be specific to I $\mathrm{K} \mathrm{B} \alpha$, and there is evidence that some of its pro-apoptotic activity may be independent of NFKB inhibition (162, 164, 170-173).

SMAC/DIABLO mimetics have recently been tested in preclinical and clinical studies for MF, with some encouraging results. SMAC inhibits endogenous inhibitor of apoptosis proteins (IAPs, also called BIRC family proteins). IAPs are ubiquitin ligases, which ubiquitinate the pro-apoptotic Complex I scaffold RIP1 and the non-canonical NFKB activating kinase NIK (NEMO-independent kinase), targeting these proteins for degradation (174). SMAC/ DIABLO mimetics, by inhibiting IAPs, promote cell death in the presence of TNF or FAS (175-179). Two such compounds, birinapant and LCL-161, (Figure 3B) were observed pre-clinically to have an inhibitory effect on myeloid colony formation specific to MF, rather than healthy control, CD34+ HSPCs $(96,180)$. In a recently completed Phase II study of LCL-161, encouraging activity was observed, with an overall response rate of $32 \%(15 / 47)$ in patients with MF who were refractory or intolerant to JAK inhibitor therapy $(174,181)$.

Casein kinase 2 (CK2) phosphorylates RELA on serine 529 (S529). While RELA phosphorylation on S536 has been more thoroughly researched, we have observed that the two phosphorylation events were interdependent in the JAK2 V617F mutant human erythroleukemia (HEL) cell line (33). Inhibition of CK2 with CX-4945 in human AML cell lines and primary AML CD34+ cells ex vivo was shown to induce cell cycle arrest, with downregulation of active RELA, AKT, and pSTAT3 (182). This represents a pharmacologic inhibition of NFKB that also might be adapted to MPN treatment.

Other potential therapeutic targets for anti-inflammatory therapy in MF include TLRs and their endogenous ligands, and IL-8/CXCL8, along its receptor CXCR2 and downstream signaling. Several endogenous TLR ligands of the S100 family were found to be overexpressed in MF versus normal CD34+ $\operatorname{HSPC}(33,48,77)$. Laouedj et al. showed that the ratio of S100A8 to S100A9 mediates a balance between immature cell proliferation, promoted by S100A8, versus myeloid differentiation, promoted by S100A9, in HOXA9-MEIS1 and MLL-AF9 AML mouse models (183). While both S100A8 and S100A9, as well as other related S100 isoforms, were found to be comparably overexpressed in MF versus normal CD34+ HSPC (48), altering the balance between them might prove to be therapeutically useful. There is not currently, however, a known pharmacologic strategy to manipulate the S100A8: S100A9 ratio, and indeed, the mechanism based on which high S100A8 expression and high S100A8:S100A9 ratio are poor prognostic indicators in AML remains unknown (183).

Overproduction of IL-8/CXCL8 was observed to be a poor prognostic feature in $\mathrm{MF}$, particularly with respect to sAML transformation, and IL-8/CXCL8 is often highly expressed in MF CD34+ HSPC as well as monocytes $(43,48)$. High expression of its receptor CXCR2 was found to be an adverse prognostic indicator for survival in AML and transfusion dependence in 
MDS (56). CXCR2 activation by IL-8/CXCL8 was shown to activate MAPK/PI3K signaling pathways, leading to proliferative and pro-survival effects in AML CD34+ $\operatorname{HSPC}(56,184)$. Therefore, any of IL-8/CXCL8, CXCR2, or downstream signaling, are plausible therapeutic targets for MPNs.

\section{UNANSWERED QUESTIONS IN MPN INFLAMMATORY PATHOPHYSIOLOGY AND TREATMENT}

MPNs can be clearly described as systemic inflammatory diseases of the hematopoietic system, as well as neoplastic diseases. Despite substantial recent progress in understanding the inflammatory components of MPN pathophysiology, a number of unanswered questions remain, whose answering might contribute to substantial improvements in MPN treatment.

The first question concerns treatment modalities. JAK inhibitors counteract the primary molecular defect common among MPNs, and, while substantially improving quality of life for many patients, they only modestly impact clonal burden or long-term outcomes $(68,79,185,186)$. IFN $\alpha$ therapy, in contrast, can reduce malignant clonal burden in individual patients, despite having proinflammatory activity and substantial systemic inflammatory toxicity, resulting in poor tolerability for many patients (187-193). Why do these therapeutic agents have relative effects on clonal burden that are discordant with what might be intuitively expected based on their molecular targets? While there is some hope that a pro-apoptotic therapy with greater efficacy against the malignant clone than against residual benign hematopoiesis might be achievable, particularly leveraging differential responses to TNF and $\mathrm{NFKB}$ between malignant and benign hematopoiesis $(53,96)$, such therapies are only in their initial experimental stages, in clinical Phase I/II trials. It is not clear whether a pro-apoptotic or antiinflammatory approach can be successful, even in combination with ruxolitinib, hydroxyurea, or IFNo. In some secondary MF patients, active hematopoiesis derives almost exclusively from the malignant clone. An important question is whether in this set of patients, restoring benign hematopoiesis is possible.

A second question derives from the evidence that the malignant clone effectively poisons the bone marrow microenvironment. In MPN mouse models, there is already evidence that this may be occurring in a step-wise manner, with sequential pathologic changes occurring in the bone marrow, with each step depending on one or more of those preceding it (128). Is there a sequential chain reaction of pathophysiologic events in human MPN disease progression that can be assaulted at its early stages to prevent (or, at minimum, make

\section{REFERENCES}

1. Falanga A, Marchetti M, Vignoli A, Balducci D, Russo L, Guerini V, et al. V617F JAK-2 Mutation in Patients With Essential Thrombocythemia: Relation to Platelet, Granulocyte, and Plasma Hemostatic and Inflammatory Molecules. Exp Hematol (2007) 35(5):702-11. doi: 10.1016/ j.exphem.2007.01.053 less likely) disease progression to MF or sAML? Determining this will require a great deal of further pathologic study of MPN bone marrow samples, including comparison of ET and PV to MF samples, early versus advanced stage MF samples, and ideally serial biopsies from individual patients. In a JAK2 V617F mouse model, Arranz et al. showed, perhaps surprisingly, that loss of sympathetic innervation was a relatively early, and crucial, event in the pathologic remodeling of MPN bone marrow (Figure 7B): indeed, hematopoietic secretion of Il-1 $\beta$ was the only antecedent even in the chain reaction identified in their study (128). Is the progression of pathologic events similar or different in human patients? If it proves similar, this would be a strong case for antiinflammatory therapy being applied not only to MF but also to ET and PV, on the theory that bone marrow inflammation represented an early event in the progression leading up to the bone marrow microenvironment becoming hostile to benign hematopoiesis while remaining receptive to malignant hematopoiesis.

A third question is whether similar, or different, therapeutics will be needed for different stages of disease progression. Blast phase, or sAML, may require cytoreductive chemotherapy, and lasting remissions from sAML have been rare $(28,40)$. If sAML remission is achievable, will either sAML in remission or MF ever be curable by means other than allogeneic hematopoietic stem cell transplant? And if so, would a therapy to eliminate a diminutive malignant clone in the case of minimal residual disease even plausibly be the same as what might eradicate a malignant clone in MF, which would usually contribute the majority, or even a neartotality, of hematopoietic cell production? It seems certain that these vastly different disease states would require substantially different treatment modifications, even if there were a common element to the otherwise diverse treatments. But would a common element be possible? A one-size-fits-all treatment is not likely to be effective for all stages of MPNs. Rather, there remains the hope that some selective treatment targeting the malignant clone might be useful at multiple stages, in conjunction with stage-specific treatments to be used in combination therapy - JAK inhibitors, anti-inflammatory agents, pro-apoptotic agents, and other signaling inhibitors wherein might lie some hope for patients to be cured pharmacologically rather than exclusively by transplant.

\section{AUTHOR CONTRIBUTIONS}

All authors contributed to writing and editing the manuscript. Figures were prepared by DF and tables were prepared by JF. All authors contributed to the article and approved the submitted version.

2. Campbell PJ, Scott LM, Buck G, Wheatley K, East CL, Marsden JT, et al. Definition of Subtypes of Essential Thrombocythaemia and Relation to Polycythaemia Vera Based on JAK2 V617F Mutation Status: A Prospective Study. Lancet (2005) 366(9501):1945-53. doi: 10.1016/S0140-6736(05)67785-9

3. Vannucchi AM, Guglielmelli P. JAK2 Mutation-Related Disease and Thrombosis. Semin Thromb Hemost (2013) 39(5):496-506. doi: 10.1055/s0033-1343890 
4. Geyer HL, Dueck AC, Scherber RM, Mesa RA. Impact of Inflammation on Myeloproliferative Neoplasm Symptom Development. Mediators Inflamm (2015) 2015:284706. doi: 10.1155/2015/284706

5. Barbui T, Finazzi G, Falanga A. Myeloproliferative Neoplasms and Thrombosis. Blood (2013) 122(13):2176-84. doi: 10.1182/blood-2013-03460154

6. Hasselbalch HC. Perspectives on Chronic Inflammation in Essential Thrombocythemia, Polycythemia Vera, and Myelofibrosis: Is Chronic Inflammation a Trigger and Driver of Clonal Evolution and Development of Accelerated Atherosclerosis and Second Cancer? Blood (2012) 119 (14):3219-25. doi: 10.1182/blood-2011-11-394775

7. Mantovani A, Allavena P, Sica A, Balkwill F. Cancer-Related Inflammation. Nature (2008) 454(7203):436-44. doi: 10.1038/nature07205

8. Martin DN, Mikhail IS, Landgren O. Autoimmunity and Hematologic Malignancies: Associations and Mechanisms. Leuk Lymphoma (2009) 50 (4):541-50. doi: 10.1080/10428190902780677

9. Kristinsson SY, Björkholm M, Hultcrantz M, Derolf Å, Landgren O, Goldin LR. Chronic Immune Stimulation Might Act as a Trigger for the Development of Acute Myeloid Leukemia or Myelodysplastic Syndromes. J Clin Oncol (2011) 29(21):2897-903. doi: 10.1200/JCO.2011.34.8540

10. Al Ustwani O, Ford LA, Sait SJ, Block AM, Barcos M, Vigil CE, et al. Myelodysplastic Syndromes and Autoimmune Diseases-Case Series and Review of Literature. Leuk Res (2013) 37(8):894-9. doi: 10.1016/ j.leukres.2013.04.007

11. Kristinsson SY, Landgren O, Samuelsson J, Björkholm M, Goldin LR. Autoimmunity and the Risk of Myeloproliferative Neoplasms. Haematologica (2010) 95(7):1216-20. doi: 10.3324/haematol.2009.020412

12. Fleischman AG. Inflammation as a Driver of Clonal Evolution in Myeloproliferative Neoplasm. Mediators Inflamm (2015) 2015:606819. doi: 10.1155/2015/606819

13. Van Egeren D, Escabi J, Nguyen M, Liu S, Reilly CR, Patel S, et al. Reconstructing the Lineage Histories and Differentiation Trajectories of Individual Hematopoietic Stem Cells in JAK2-Mutant Myeloproliferative Neoplasms. Blood (2020) 136(Supplement 1):7-8. doi: 10.1182/blood-2020-141643

14. Williams N, Lee J, Moore L, Baxter JE, Hewinson J, Dawson KJ, et al. Driver Mutation Acquisition in Utero and Childhood Followed By Lifelong Clonal Evolution Underlie Myeloproliferative Neoplasms. Blood (2020) 136 (Supplement_2):LBA-1-LBA-1. doi: 10.1182/blood-2020-143813

15. Stengel A, Baer C, Walter W, Meggendorfer M, Kern W, Haferlach T, et al. Mutational Patterns and Correlation to Chip-Related Mutations in Hematological Malignancies - A Study on Mutation Frequencies of 122 Genes in 28 Entities Including 3096 Cases. Blood (2020) 136(Supplement 1):37-8. doi: 10.1182/blood-2020-136288

16. Van Egeren D, Escabi J, Nguyen M, Liu S, Reilly CR, Patel S, et al. Reconstructing the Lineage Histories and Differentiation Trajectories of Individual Cancer Cells in Myeloproliferative Neoplasms. Cell Stem Cell (2021) 28(3):514-523.e9. doi: 10.1016/j.stem.2021.02.001

17. Williams N, Lee J, Moore L, Baxter EJ, Hewinson J, Dawson KJ, et al. Phylogenetic Reconstruction of Myeloproliferative Neoplasm Reveals Very Early Origins and Lifelong Evolution. bioRxiv (2020). doi: 10.1101/ 2020.11.09.374710

18. O'Sullivan J, Mead AJ. Heterogeneity in Myeloproliferative Neoplasms: Causes and Consequences. Adv Biol Regul (2019) 71:55-68. doi: 10.1016/ j.jbior.2018.11.007

19. Chen E, Beer PA, Godfrey AL, Ortmann CA, Li J, Costa-Pereira AP, et al. Distinct Clinical Phenotypes Associated With JAK2V617F Reflect Differential STAT1 Signaling. Cancer Cell (2010) 18(5):524-35. doi: 10.1016/j.ccr.2010.10.013

20. Larsen TS, Pallisgaard N, Møller MB, Hasselbalch HC. The JAK2 V617F Allele Burden in Essential Thrombocythemia, Polycythemia Vera and Primary Myelofibrosis-Impact on Disease Phenotype. Eur J Haematol (2007) 79(6):508-15. doi: 10.1111/j.1600-0609.2007.00960.x

21. Vannucchi AM, Antonioli E, Guglielmelli P, Pardanani A, Tefferi A. Clinical Correlates of JAK2V617F Presence or Allele Burden in Myeloproliferative Neoplasms: A Critical Reappraisal. Leukemia (2008) 22(7):1299-307. doi: 10.1038/leu.2008.113

22. Vannucchi AM, Antonioli E, Guglielmelli P, Longo G, Pancrazzi A, Ponziani V, et al. Prospective Identification of High-Risk Polycythemia Vera Patients
Based on JAK2(V617F) Allele Burden. Leukemia (2007) 21(9):1952-9. doi: $10.1038 /$ sj.leu.2404854

23. Barbui T, Carobbio A, Finazzi G, Vannucchi AM, Barosi G, Antonioli E, et al. Investigators: Inflammation and Thrombosis in Essential Thrombocythemia and Polycythemia Vera: Different Role of C-reactive Protein and Pentraxin 3. Haematologica (2011) 96(2):315-8. doi: 10.3324/ haematol.2010.031070

24. Lussana F, Carobbio A, Salmoiraghi S, Guglielmelli P, Vannucchi AM, Bottazzi B, et al. Driver Mutations (JAK2V617F, MPLW515L/K or CALR), Pentraxin-3 and C-reactive Protein in Essential Thrombocythemia and Polycythemia Vera. J Hematol Oncol (2017) 10(1):54. doi: 10.1186/s13045017-0425-z

25. Barosi G, Massa M, Campanelli R, Fois G, Catarsi P, Viarengo G, et al. Primary Myelofibrosis: Older Age and High JAK2V617F Allele Burden are Associated With Elevated Plasma High-Sensitivity C-reactive Protein Levels and a Phenotype of Progressive Disease. Leuk Res (2017) 60:18-23. doi: 10.1016/j.leukres.2017.06.004

26. Barbui T, Carobbio A, Finazzi G, Guglielmelli P, Salmoiraghi S, Rosti V, et al. Elevated C-reactive Protein is Associated With Shortened Leukemia-Free Survival in Patients With Myelofibrosis. Leukemia (2013) 27(10):2084-6. doi: 10.1038/leu.2013.207

27. Barosi G, Klersy C, Villani L, Bonetti E, Catarsi P, Poletto V, et al. JAK2 (V617F) Allele Burden $¥ 50 \%$ is Associated With Response to Ruxolitinib in Persons With MPN-associated Myelofibrosis and Splenomegaly Requiring Therapy. Leukemia (2016) 30(8):1772-5. doi: 10.1038/leu.2016.45

28. Cerquozzi S, Tefferi A. Blast Transformation and Fibrotic Progression in Polycythemia Vera and Essential Thrombocythemia: A Literature Review of Incidence and Risk Factors. Blood Cancer J (2015) 5:e366. doi: 10.1038/ bcj. 2015.95

29. Nangalia J, Massie CE, Baxter EJ, Nice FL, Gundem G, Wedge DC, et al. Somatic CALR Mutations in Myeloproliferative Neoplasms With Nonmutated JAK2. N Engl J Med (2013) 369(25):2391-405. doi: 10.1056/ NEJMoa1312542

30. Klampfl T, Gisslinger H, Harutyunyan AS, Nivarthi H, Rumi E, Milosevic JD, et al. Somatic Mutations of Calreticulin in Myeloproliferative Neoplasms. N Engl J Med (2013) 369(25):2379-90. doi: 10.1056/ NEJMoa1311347

31. Vannucchi AM, Lasho TL, Guglielmelli P, Biamonte F, Pardanani A, Pereira A, et al. Mutations and Prognosis in Primary Myelofibrosis. Leukemia (2013) 27(9):1861-9. doi: 10.1038/leu.2013.119

32. Rumi E, Pietra D, Pascutto C, Guglielmelli P, Martínez-Trillos A, Casetti I, et al. Clinical Effect of Driver Mutations of JAK2, CALR, or MPL in Primary Myelofibrosis. Blood (2014) 124(7):1062-9. doi: 10.1182/blood-2014-05578435

33. Fisher DAC, Malkova O, Engle EK, Miner CA, Fulbright MC, Behbehani GK, et al. Mass Cytometry Analysis Reveals Hyperactive NF Kappa B Signaling in Myelofibrosis and Secondary Acute Myeloid Leukemia. Leukemia (2017) 31(9):1962-74. doi: 10.1038/leu.2016.377

34. Vannucchi AM, Rotunno G, Bartalucci N, Raugei G, Carrai V, Balliu M, et al. Calreticulin Mutation-Specific Immunostaining in Myeloproliferative Neoplasms: Pathogenetic Insight and Diagnostic Value. Leukemia (2014) 28 (9):1811-8. doi: 10.1038/leu.2014.100

35. Barosi G, Campanelli R, Catarsi P, De Amici M, Abbà C, Viarengo G, et al. Plasma Sil-2R $\alpha$ Levels are Associated With Disease Progression in Myelofibrosis With JAK2. Leuk Res (2020) 90:106319. doi: 10.1016/ j.leukres.2020.106319

36. Zhou A, Oh ST. Prognostication in MF: From CBC to Cytogenetics to Molecular Markers. Best Pract Res Clin Haematol (2014) 27(2):155-64. doi: 10.1016/j.beha.2014.07.008

37. Tefferi A, Lasho TL, Huang J, Finke C, Mesa RA, Li CY, et al. Low JAK2V617F Allele Burden in Primary Myelofibrosis, Compared to Either a Higher Allele Burden or Unmutated Status, is Associated With Inferior Overall and Leukemia-Free Survival. Leukemia (2008) 22(4):756-61. doi: $10.1038 /$ sj.leu. 2405097

38. Guglielmelli P, Barosi G, Specchia G, Rambaldi A, Lo Coco F, Antonioli E, et al. Identification of Patients With Poorer Survival in Primary Myelofibrosis Based on the Burden of JAK2V617F Mutated Allele. Blood (2009) 114(8):1477-83. doi: 10.1182/blood-2009-04-216044 
39. Guglielmelli P, Lasho TL, Rotunno G, Score J, Mannarelli C, Pancrazzi A, et al. The Number of Prognostically Detrimental Mutations and Prognosis in Primary Myelofibrosis: An International Study of 797 Patients. Leukemia (2014) 28(9):1804-10. doi: 10.1038/leu.2014.76

40. Zhou A, Afzal A, Oh ST. Prognostication in Philadelphia Chromosome Negative Myeloproliferative Neoplasms: A Review of the Recent Literature. Curr Hematol Malig Rep (2017) 12(5):397-405. doi: 10.1007/s11899-0170401-2

41. Fowles JS, How J, Allen MJ, Oh ST. Young Versus Old Age at Diagnosis Confers Distinct Genomic Profiles in Patients With Polycythemia Vera. Leukemia (2019) 33(6):1522-6. doi: 10.1038/s41375-018-0349-9

42. Pardanani A, Begna K, Finke C, Lasho T, Tefferi A. Circulating Levels of MCP-1, Sil-2R, IL-15, and IL-8 Predict Anemia Response to Pomalidomide Therapy in Myelofibrosis. Am J Hematol (2011) 86(4):343-5. doi: 10.1002/ ajh. 21972

43. Tefferi A, Vaidya R, Caramazza D, Finke C, Lasho T, Pardanani A. Circulating Interleukin (IL)-8, IL-2R, Il-12, and IL-15 Levels are Independently Prognostic in Primary Myelofibrosis: A Comprehensive Cytokine Profiling Study. J Clin Oncol (2011) 29(10):1356-63. doi: $10.1200 /$ jco.2010.32.9490

44. Vaidya R, Gangat N, Jimma T, Finke CM, Lasho TL, Pardanani A, et al. Plasma Cytokines in Polycythemia Vera: Phenotypic Correlates, Prognostic Relevance, and Comparison With Myelofibrosis. Am J Hematol (2012) 87 (11):1003-5. doi: 10.1002/ajh.23295

45. Kalota A, Jeschke GR, Carroll M, Hexner EO. Intrinsic Resistance to JAK2 Inhibition in Myelofibrosis. Clin Cancer Res (2013) 19(7):1729-39. doi: 10.1158/1078-0432.ccr-12-1907

46. Pourcelot E, Trocme C, Mondet J, Bailly S, Toussaint B, Mossuz P. Cytokine Profiles in Polycythemia Vera and Essential Thrombocythemia Patients: Clinical Implications. Exp Hematol (2014) 42(5):360-8. doi: 10.1016/ j.exphem.2014.01.006

47. Cacemiro MDC, Cominal JG, Tognon R, Nunes NS, Simoes BP, FigueiredoPontes LL, et al. Philadelphia-Negative Myeloproliferative Neoplasms as Disorders Marked by Cytokine Modulation. Hematol Transfus Cell Ther (2018) 40(2):120-31. doi: 10.1016/j.htct.2017.12.003

48. Fisher DAC, Miner CA, Engle EK, Hu H, Collins TB, Zhou A, et al. Cytokine Production in Myelofibrosis Exhibits Differential Responsiveness to JAKSTAT, MAP Kinase, and NFkappaB Signaling. Leukemia (2019) 33(8):197895. doi: 10.1038/s41375-019-0379-y

49. Boissinot M, Cleyrat C, Vilaine M, Jacques Y, Corre I, Hermouet S. AntiInflammatory Cytokines Hepatocyte Growth Factor and Interleukin-11 are Over-Expressed in Polycythemia Vera and Contribute to the Growth of Clonal Erythroblasts Independently of JAK2V617F. Oncogene (2011) 30 (8):990-1001. doi: 10.1038/onc.2010.479

50. Panteli KE, Hatzimichael EC, Bouranta PK, Katsaraki A, Seferiadis K, Stebbing J, et al. Serum Interleukin (IL)-1, IL-2, Sil-2Ra, IL-6 and Thrombopoietin Levels in Patients With Chronic Myeloproliferative Diseases. Br J Haematol (2005) 130 (5):709-15. doi: 10.1111/j.1365-2141.2005.05674.x

51. Bourantas KL, Hatzimichael EC, Makis AC, Chaidos A, Kapsali ED, Tsiara S, et al. Serum Beta-2-Microglobulin, TNF-alpha and Interleukins in Myeloproliferative Disorders. Eur J Haematol (1999) 63(1):19-25. doi: 10.1111/j.1600-0609.1999.tb01845.x

52. Barabanshikova MV, Dubina IA, Lapin SV, Morozova EV, Vlasova JJ, Ivanova MO, et al. Clinical Correlates and Prognostic Significance of IL-8, sIL-2R, and Immunoglobulin-Free Light Chain Levels in Patients With Myelofibrosis. Oncol Res Treat (2017) 40(10):574-8. doi: 10.1159/000477253

53. Fleischman AG, Aichberger KJ, Luty SB, Bumm TG, Petersen CL, Doratotaj S, et al. TNFalpha Facilitates Clonal Expansion of JAK2V617F Positive Cells in Myeloproliferative Neoplasms. Blood (2011) 118(24):6392-8. doi: 10.1182/blood-2011-04-348144

54. Koschmieder S, Mughal TI, Hasselbalch HC, Barosi G, Valent P, Kiladjian JJ, et al. Myeloproliferative Neoplasms and Inflammation: Whether to Target the Malignant Clone or the Inflammatory Process or Both. Leukemia (2016) 30(5):1018-24. doi: 10.1038/leu.2016.12

55. Kawatani T, Endo A, Tajima F, Ooi S, Kawasaki H. Clinical Significance of Serum Soluble Interleukin-2 Receptor in Chronic Myeloproliferative Disorders. Int J Hematol (1997) 65(2):123-8. doi: 10.1016/s0925-5710(96) 00554-3
56. Schinke C, Giricz O, Li W, Shastri A, Gordon S, Barreyro L, et al. IL8-CXCR2 Pathway Inhibition as a Therapeutic Strategy Against MDS and AML Stem Cells. Blood (2015) 125(20):3144-52. doi: 10.1182/blood-2015-01-621631

57. Verstovsek S, Kantarjian H, Mesa RA, Pardanani AD, Cortes-Franco J, Thomas DA, et al. Safety and Efficacy of INCB018424, a JAK1 and JAK2 Inhibitor, in Myelofibrosis. N Engl J Med (2010) 363(12):1117-27. doi: 10.1056/NEJMoa1002028

58. Chen E, Ahn JS, Massie CE, Clynes D, Godfrey AL, Li J, et al. JAK2V617F Promotes Replication Fork Stalling With Disease-Restricted Impairment of the Intra-s Checkpoint Response. Proc Natl Acad Sci U S A (2014) 111 (42):15190-5. doi: 10.1073/pnas.1401873111

59. Spivak JL. Myeloproliferative Neoplasms. N Engl J Med (2017) 376 (22):2168-81. doi: 10.1056/NEJMra1406186

60. Vainchenker W, Kralovics R. Genetic Basis and Molecular Pathophysiology of Classical Myeloproliferative Neoplasms. Blood (2017) 129(6):667-79. doi: 10.1182/blood-2016-10-695940

61. Elf S, Abdelfattah NS, Chen E, Perales-Paton J, Rosen EA, Ko A, et al. Mutant Calreticulin Requires Both its Mutant C-Terminus and the Thrombopoietin Receptor for Oncogenic Transformation. Cancer Discov (2016) 6(4):368-81. doi: 10.1158/2159-8290.cd-15-1434

62. Oh ST, Simonds EF, Jones C, Hale MB, Goltsev Y, Gibbs KDJr., et al. Novel Mutations in the Inhibitory Adaptor Protein LNK Drive JAK-STAT Signaling in Patients With Myeloproliferative Neoplasms. Blood (2010) 116(6):988-92. doi: 10.1182/blood-2010-02-270108

63. Pardanani A, Lasho T, Finke C, Oh ST, Gotlib J, Tefferi A. LNK Mutation Studies in Blast-Phase Myeloproliferative Neoplasms, and in Chronic-Phase Disease With TET2, IDH, JAK2 or MPL Mutations. Leukemia (2010) 24 (10):1713-8. doi: 10.1038/leu.2010.163

64. Harrison CN, Mead AJ, Panchal A, Fox S, Yap C, Gbandi E, et al. Ruxolitinib vs Best Available Therapy for ET Intolerant or Resistant to Hydroxycarbamide. Blood (2017) 130(17):1889-97. doi: 10.1182/blood-2017-05-785790

65. Vannucchi AM, Kiladjian JJ, Griesshammer M, Masszi T, Durrant S, Passamonti F, et al. Ruxolitinib Versus Standard Therapy for the Treatment of Polycythemia Vera. N Engl J Med (2015) 372(5):426-35. doi: 10.1056/NEJMoa1409002

66. Verstovsek S, Passamonti F, Rambaldi A, Barosi G, Rumi E, Gattoni E, et al. Ruxolitinib for Essential Thrombocythemia Refractory to or Intolerant of Hydroxyurea: Long-Term Phase 2 Study Results. Blood (2017) 130 (15):1768-71. doi: 10.1182/blood-2017-02-765032

67. Vannucchi AM. Ruxolitinib Versus Standard Therapy for the Treatment of Polycythemia Vera. N Engl J Med (2015) 372(17):1670-1. doi: 10.1056/ NEJMc1502524

68. Verstovsek S, Gotlib J, Mesa RA, Vannucchi AM, Kiladjian JJ, Cervantes F, et al. Long-Term Survival in Patients Treated With Ruxolitinib for Myelofibrosis: COMFORT-I and -II Pooled Analyses. J Hematol Oncol (2017) 10(1):156. doi: 10.1186/s13045-017-0527-7

69. Hasselbalch HC, Bjørn ME. Ruxolitinib Versus Standard Therapy for the Treatment of Polycythemia Vera. N Engl J Med (2015) 372(17):1670. doi: 10.1056/NEJMc1502524

70. Griesshammer M, Sadjadian P. The BCR-ABL1-negative Myeloproliferative Neoplasms: A Review of JAK Inhibitors in the Therapeutic Armamentarium. Expert Opin Pharmacother (2017) 18(18):1929-38. doi: 10.1080/ 14656566.2017.1404574

71. Verstovsek S, Manshouri T, Pilling D, Bueso-Ramos CE, Newberry KJ, Prijic $\mathrm{S}$, et al. Role of Neoplastic Monocyte-Derived Fibrocytes in Primary Myelofibrosis. J Exp Med (2016) 213(9):1723-40. doi: 10.1084/jem.20160283

72. Gibbs KDJr., Gilbert PM, Sachs K, Zhao F, Blau HM, Weissman IL, et al. Single-Cell Phospho-Specific Flow Cytometric Analysis Demonstrates Biochemical and Functional Heterogeneity in Human Hematopoietic Stem and Progenitor Compartments. Blood (2011) 117(16):4226-33. doi: 10.1182/ blood-2010-07-298232

73. Rodriguez-Meira A, Buck G, Clark SA, Povinelli BJ, Alcolea V, Louka E, et al. Unravelling Intratumoral Heterogeneity Through High-Sensitivity SingleCell Mutational Analysis and Parallel RNA Sequencing. Mol Cell (2019) 73 (6):1292-1305.e8. doi: 10.1016/j.molcel.2019.01.009

74. Chagraoui H, Komura E, Tulliez M, Giraudier S, Vainchenker W, Wendling F. Prominent Role of TGF-beta 1 in Thrombopoietin-Induced Myelofibrosis in Mice. Blood (2002) 100(10):3495-503. doi: 10.1182/blood-2002-04-1133 
75. Mullally A, Lane SW, Brumme K, Ebert BL. Myeloproliferative Neoplasm Animal Models. Hematol Oncol Clin North Am (2012) 26(5):1065-81. doi: 10.1016/j.hoc.2012.07.007

76. Hasselbalch HC, Bjørn ME. MPNs as Inflammatory Diseases: The Evidence, Consequences, and Perspectives. Mediators Inflamm (2015) 2015:102476. doi: $10.1155 / 2015 / 102476$

77. Norfo R, Zini R, Pennucci V, Bianchi E, Salati S, Guglielmelli P, et al. miRNA-mRNA Integrative Analysis in Primary Myelofibrosis CD34+ Cells: Role of miR-155/JARID2 Axis in Abnormal Megakaryopoiesis. Blood (2014) 124(13):e21-32. doi: 10.1182/blood-2013-12-544197

78. Delhommeau F, Dupont S, Tonetti C, Masse A, Godin I, Le Couedic JP, et al. Evidence That the JAK2 G1849T (V617F) Mutation Occurs in a Lymphomyeloid Progenitor in Polycythemia Vera and Idiopathic Myelofibrosis. Blood (2007) 109(1):71-7. doi: 10.1182/blood-2006-03007146

79. Deininger M, Radich J, Burn TC, Huber R, Paranagama D, Verstovsek S. The Effect of Long-Term Ruxolitinib Treatment on JAK2p.V617F Allele Burden in Patients with Myelofibrosis. Blood (2015) 126(13):1551-4. doi: 10.1182/ blood-2015-03-635235

80. Kvasnicka HM, Thiele J, Bueso-Ramos CE, Sun W, Cortes J, Kantarjian HM, et al. Long-Term Effects of Ruxolitinib Versus Best Available Therapy on Bone Marrow Fibrosis in Patients With Myelofibrosis. J Hematol Oncol (2018) 11(1):42. doi: 10.1186/s13045-018-0585-5

81. Dostert C, Grusdat M, Letellier E, Brenner D. The TNF Family of Ligands and Receptors: Communication Modules in the Immune System and Beyond. Physiol Rev (2019) 99(1):115-60. doi: 10.1152/physrev.00045.2017

82. Kagoya Y, Yoshimi A, Kataoka K, Nakagawa M, Kumano K, Arai S, et al. Positive Feedback Between NF-kappaB and TNF-alpha Promotes LeukemiaInitiating Cell Capacity. J Clin Invest (2014) 124(2):528-42. doi: 10.1172/ JCI68101

83. Ishikawa G, Fujiwara N, Hirschfield H, Varricchio L, Hoshida Y, Barosi G, et al. Shared and Tissue-Specific Expression Signatures Between Bone Marrow From Primary Myelofibrosis and Essential Thrombocythemia. Exp Hematol (2019) 79:16-25.e3. doi: 10.1016/j.exphem.2019.10.001

84. Kleppe M, Koche R, Zou L, van Galen P, Hill CE, Dong L, et al. Dual Targeting of Oncogenic Activation and Inflammatory Signaling Increases Therapeutic Efficacy in Myeloproliferative Neoplasms. Cancer Cell (2017) 21:489-501. doi: 10.1016/j.ccell.2017.11.009

85. Jacquelin S, Straube J, Cooper L, Vu T, Song A, Bywater M, et al. Jak2V617F and Dnmt3a Loss Cooperate to Induce Myelofibrosis Through Activated Enhancer-Driven Inflammation. Blood (2018) 132(26):2707-21. doi: 10.1182/blood-2018-04-846220

86. Kleppe M, Kwak M, Koppikar P, Riester M, Keller M, Bastian L, et al. JAKSTAT Pathway Activation in Malignant and Nonmalignant Cells Contributes to MPN Pathogenesis and Therapeutic Response. Cancer Discov (2015) 5(3):316-31. doi: 10.1158/2159-8290.CD-14-0736

87. Vannucchi AM, Bianchi L, Paoletti F, Pancrazzi A, Torre E, Nishikawa M, et al. A Pathobiologic Pathway Linking Thrombopoietin, GATA-1, and TGF-beta1 in the Development of Myelofibrosis. Blood (2005) 105(9):3493501. doi: 10.1182/blood-2004-04-1320

88. Wagner-Ballon O, Chagraoui H, Prina E, Tulliez M, Milon G, Raslova H, et al. Monocyte/Macrophage Dysfunctions do Not Impair the Promotion of Myelofibrosis by High Levels of Thrombopoietin. J Immunol (2006) 176 (11):6425-33. doi: 10.4049/jimmunol.176.11.6425

89. Wen QJ, Yang Q, Goldenson B, Malinge S, Lasho T, Schneider RK, et al. Targeting Megakaryocytic-Induced Fibrosis in Myeloproliferative Neoplasms by AURKA Inhibition. Nat Med (2015) 21(12):1473-80. doi: $10.1038 / \mathrm{nm} .3995$

90. Craver BM, El Alaoui K, Scherber RM, Fleischman AG. The Critical Role of Inflammation in the Pathogenesis and Progression of Myeloid Malignancies. Cancers (Basel) (2018) 10(4):104. doi: 10.3390/cancers10040104

91. Cabal-Hierro L, Lazo PS. Signal Transduction by Tumor Necrosis Factor Receptors. Cell Signal (2012) 24(6):1297-305. doi: 10.1016/ j.cellsig.2012.02.006

92. Zhao JL, Ma C, O'Connell RM, Mehta A, DiLoreto R, Heath JR, et al. Conversion of Danger Signals Into Cytokine Signals by Hematopoietic Stem and Progenitor Cells for Regulation of Stress-Induced Hematopoiesis. Cell Stem Cell (2014) 14(4):445-59. doi: 10.1016/j.stem.2014.01.007
93. Sejas DP, Rani R, Qiu Y, Zhang X, Fagerlie SR, Nakano H, et al. Inflammatory Reactive Oxygen Species-Mediated Hemopoietic Suppression in Fancc-Deficient Mice. J Immunol (2007) 178(8):5277-87. doi: 10.4049/jimmunol.178.8.5277

94. Li J, Sejas DP, Zhang X, Qiu Y, Nattamai KJ, Rani R, et al. TNF-Alpha Induces Leukemic Clonal Evolution Ex Vivo in Fanconi Anemia Group C Murine Stem Cells. J Clin Invest (2007) 117(11):3283-95. doi: 10.1172/ jci31772

95. Yamashita M, Passegué E. TNF- $\alpha$ Coordinates Hematopoietic Stem Cell Survival and Myeloid Regeneration. Cell Stem Cell (2019) 25(3):357-72.e7. doi: 10.1016/j.stem.2019.05.019

96. Heaton WL, Senina AV, Pomicter AD, Salama ME, Clair PM, Yan D, et al. Autocrine Tnf Signaling Favors Malignant Cells in Myelofibrosis in a Tnfr2dependent Fashion. Leukemia (2018) 32:2399-411. doi: 10.1038/s41375018-0131-z

97. Volk A, Li J, Xin J, You D, Zhang J, Liu X, et al. Co-Inhibition of NF-kappaB and JNK is Synergistic in TNF-expressing Human AML. J Exp Med (2014) 211(6):1093-108. doi: 10.1084/jem.20130990

98. Stetka J, Vyhlidalova P, Lanikova L, Koralkova P, Gursky J, Hlusi A, et al. Addiction to DUSP1 Protects JAK2V617F-driven Polycythemia Vera Progenitors Against Inflammatory Stress and DNA Damage, Allowing Chronic Proliferation. Oncogene (2019) 38(28):5627-42. doi: 10.1038/ s41388-019-0813-7

99. Pronk CJ, Veiby OP, Bryder D, Jacobsen SE. Tumor Necrosis Factor Restricts Hematopoietic Stem Cell Activity in Mice: Involvement of Two Distinct Receptors. J Exp Med (2011) 208(8):1563-70. doi: 10.1084/ jem.20110752

100. Xiao Y, Li H, Zhang J, Volk A, Zhang S, Wei W, et al. TNF-Alpha/Fas-RIP-1induced Cell Death Signaling Separates Murine Hematopoietic Stem Cells/ Progenitors Into 2 Distinct Populations. Blood (2011) 118(23):6057-67. doi: 10.1182/blood-2011-06-359448

101. Abegunde SO, Buckstein R, Wells RA, Rauh MJ. An Inflammatory Environment Containing TNFalpha Favors Tet2-mutant Clonal Hematopoiesis. Exp Hematol (2018) 59:60-5. doi: 10.1016/ j.exphem.2017.11.002

102. Cull AH, Snetsinger B, Buckstein R, Wells RA, Rauh MJ. Tet2 Restrains Inflammatory Gene Expression in Macrophages. Exp Hematol (2017) 55:5670.e13. doi: 10.1016/j.exphem.2017.08.001

103. Ortmann CA, Kent DG, Nangalia J, Silber Y, Wedge DC, Grinfeld J, et al. Effect of Mutation Order on Myeloproliferative Neoplasms. $N$ Engl J Med (2015) 372(7):601-12. doi: 10.1056/NEJMoa1412098

104. Swierczek SI, Yoon D, Bellanne-Chantelot C, Kim SJ, Saint-Martin C, Delhommeau F, et al. Extent of Hematopoietic Involvement by TET2 Mutations in JAK2V(6)(1)(7)F Polycythemia Vera. Haematologica (2011) 96(5):775-8. doi: 10.3324/haematol.2010.029678

105. Kent DG, Li J, Tanna H, Fink J, Kirschner K, Pask DC, et al. Self-Renewal of Single Mouse Hematopoietic Stem Cells is Reduced by JAK2V617F Without Compromising Progenitor Cell Expansion. PloS Biol (2013) 11(6):e1001576. doi: 10.1371/journal.pbio.1001576

106. Kennedy R, Klein U. Aberrant Activation of NF-אB Signalling in Aggressive Lymphoid Malignancies. Cells (2018) 7(11):1-22. doi: 10.3390/cells7110189

107. Guzman ML, Neering SJ, Upchurch D, Grimes B, Howard DS, Rizzieri DA, et al. Nuclear Factor-KappaB is Constitutively Activated in Primitive Human Acute Myelogenous Leukemia Cells. Blood (2001) 98(8):2301-7. doi: 10.1182/blood.V98.8.2301

108. Sanz C, Richard C, Prosper F, Fernandez-Luna JL. Nuclear Factor K B is Activated in Myelodysplastic Bone Marrow Cells. Haematologica (2002) 87 (9):1005-6.

109. Komura E, Tonetti C, Penard-Lacronique V, Chagraoui H, Lacout C, Lecouédic JP, et al. Role for the Nuclear Factor Kappab Pathway in Transforming Growth Factor-Betal Production in Idiopathic Myelofibrosis: Possible Relationship With FK506 Binding Protein 51 Overexpression. Cancer Res (2005) 65(8):3281-9. doi: 10.1158/0008-5472.CAN-04-2339

110. Bosman MC, Schuringa JJ, Vellenga E. Constitutive NF- $\kappa \mathrm{B}$ Activation in AML: Causes and Treatment Strategies. Crit Rev Oncol Hematol (2016) 98:35-44. doi: 10.1016/j.critrevonc.2015.10.001

111. Birkenkamp KU, Geugien M, Schepers H, Westra J, Lemmink HH, Vellenga E. Constitutive NF-kappaB DNA-Binding Activity in AML is Frequently 
Mediated by a Ras/PI3-K/PKB-dependent Pathway. Leukemia (2004) 18 (1):103-12. doi: 10.1038/sj.leu.2403145

112. Stivala S, Codilupi T, Brkic S, Baerenwaldt A, Ghosh N, Hao-Shen H, et al. Targeting Compensatory MEK/ERK Activation Increases JAK Inhibitor Efficacy in Myeloproliferative Neoplasms. J Clin Invest (2019) 130:1596611. doi: 10.1172/JCI98785

113. Buss H, Handschick K, Jurrmann N, Pekkonen P, Beuerlein K, Müller H, et al. Cyclin-Dependent Kinase 6 Phosphorylates NF-KB P65 at Serine 536 and Contributes to the Regulation of Inflammatory Gene Expression. PloS One (2012) 7(12):e51847. doi: 10.1371/journal.pone.0051847

114. Grosjean-Raillard J, Ades L, Boehrer S, Tailler M, Fabre C, Braun T, et al. Flt3 Receptor Inhibition Reduces Constitutive NFkappaB Activation in HighRisk Myelodysplastic Syndrome and Acute Myeloid Leukemia. Apoptosis (2008) 13(9):1148-61. doi: 10.1007/s10495-008-0243-4

115. Mulero MC, Wang VY, Huxford T, Ghosh G. Genome Reading by the NFкB Transcription Factors. Nucleic Acids Res (2019) 47(19):9967-89. doi: 10.1093/nar/gkz739

116. Handschick K, Beuerlein K, Jurida L, Bartkuhn M, Müller H, Soelch J, et al. Cyclin-Dependent Kinase 6 is a Chromatin-Bound Cofactor for NF- KBDependent Gene Expression. Mol Cell (2014) 53(2):193-208. doi: 10.1016/ j.molcel.2013.12.002

117. Uras IZ, Maurer B, Nivarthi H, Jodl P, Kollmann K, Prchal-Murphy M, et al. CDK6 Coordinates. Blood (2019) 133(15):1677-90. doi: 10.1182/blood2018-08-872648

118. Carey A, Edwards DK, Eide CA, Newell L, Traer E, Medeiros BC, et al. Identification of Interleukin-1 by Functional Screening as a Key Mediator of Cellular Expansion and Disease Progression in Acute Myeloid Leukemia. Cell Rep (2017) 18(13):3204-18. doi: 10.1016/j.celrep.2017.03.018

119. Pietras EM, Mirantes-Barbeito C, Fong S, Loeffler D, Kovtonyuk LV, Zhang S, et al. Chronic Interleukin-1 Exposure Drives Haematopoietic Stem Cells Towards Precocious Myeloid Differentiation at the Expense of Self-Renewal. Nat Cell Biol (2016) 18(6):607-18. doi: 10.1038/ncb3346

120. Wang A, Zhong H. Roles of the Bone Marrow Niche in Hematopoiesis, Leukemogenesis, and Chemotherapy Resistance in Acute Myeloid Leukemia. Hematology (2018) 23(10):729-39. doi: 10.1080/10245332.2018.1486064

121. Pinho S, Frenette PS. Haematopoietic Stem Cell Activity And Interactions With the Niche. Nat Rev Mol Cell Biol (2019) 20(5):303-20. doi: 10.1038/ s41580-019-0103-9

122. Shafat MS, Gnaneswaran B, Bowles KM, Rushworth SA. The Bone Marrow Microenvironment - Home of the Leukemic Blasts. Blood Rev (2017) 31 (5):277-86. doi: 10.1016/j.blre.2017.03.004

123. Leimkühler NB, Schneider RK. Inflammatory Bone Marrow Microenvironment. Hematol Am Soc Hematol Educ Program (2019) 2019 (1):294-302. doi: 10.1182/hematology.2019000045

124. Schneider RK, Mullally A, Dugourd A, Peisker F, Hoogenboezem R, Van Strien PMH, et al. Gli1. Cell Stem Cell (2017) 20(6):785-800.e8. doi: 10.1016/ j.stem.2017.03.008

125. Qian H, Buza-Vidas N, Hyland CD, Jensen CT, Antonchuk J, Månsson R, et al. Critical Role of Thrombopoietin in Maintaining Adult Quiescent Hematopoietic Stem Cells. Cell Stem Cell (2007) 1(6):671-84. doi: 10.1016/ j.stem.2007.10.008

126. Yoshihara H, Arai F, Hosokawa K, Hagiwara T, Takubo K, Nakamura Y, et al. Thrombopoietin/MPL Signaling Regulates Hematopoietic Stem Cell Quiescence and Interaction With the Osteoblastic Niche. Cell Stem Cell (2007) 1(6):685-97. doi: 10.1016/j.stem.2007.10.020

127. Ramalingam P, Poulos MG, Lazzari E, Gutkin MC, Lopez D, Kloss CC, et al. Chronic Activation of Endothelial MAPK Disrupts Hematopoiesis Via NFKB Dependent Inflammatory Stress Reversible by SCGF. Nat Commun (2020) 11(1):666. doi: 10.1038/s41467-020-14478-8

128. Arranz L, Sanchez-Aguilera A, Martin-Perez D, Isern J, Langa X, Tzankov A, et al. Neuropathy of Haematopoietic Stem Cell Niche is Essential for Myeloproliferative Neoplasms. Nature (2014) 512(7512):78-81. doi: 10.1038/nature13383

129. Nakagawa MM, Chen H, Rathinam CV. Constitutive Activation of NF- $\kappa B$ Pathway in Hematopoietic Stem Cells Causes Loss of Quiescence and Deregulated Transcription Factor Networks. Front Cell Dev Biol (2018) 6:143. doi: $10.3389 /$ fcell. 2018.00143

130. Nakagawa MM, Rathinam CV. Constitutive Activation of the Canonical Nf$\kappa \mathrm{B}$ Pathway Leads to Bone Marrow Failure and Induction of Erythroid
Signature in Hematopoietic Stem Cells. Cell Rep (2018) 25(8):2094-2109.e4. doi: 10.1016/j.celrep.2018.10.071

131. Nakagawa MM, Thummar K, Mandelbaum J, Pasqualucci L, Rathinam CV. Lack of the Ubiquitin-Editing Enzyme A20 Results in Loss of Hematopoietic Stem Cell Quiescence. J Exp Med (2015) 212(2):203-16. doi: 10.1084/ jem.20132544

132. Nakagawa MM, Davis H, Rathinam CV. A20 Deficiency in Multipotent Progenitors Perturbs Quiescence of Hematopoietic Stem Cells. Stem Cell Res (2018) 33:199-205. doi: 10.1016/j.scr.2018.10.020

133. Nakagawa MM, Rathinam CV. A20 Deficiency in Hematopoietic Stem Cells Causes Lymphopenia and Myeloproliferation Due to Elevated Interferon- $\gamma$ Signals. Sci Rep (2019) 9(1):12658. doi: 10.1038/s41598-019-49038-8

134. Nagamachi A, Nakata Y, Ueda T, Yamasaki N, Ebihara Y, Tsuji K, et al. Acquired Deficiency of A20 Results in Rapid Apoptosis, Systemic Inflammation, and Abnormal Hematopoietic Stem Cell Function. PloS One (2014) 9(1):e87425. doi: 10.1371/journal.pone.0087425

135. Poulos MG, Ramalingam P, Gutkin MC, Llanos P, Gilleran K, Rabbany SY, et al. Endothelial Transplantation Rejuvenates Aged Hematopoietic Stem Cell Function. J Clin Invest (2017) 127(11):4163-78. doi: 10.1172/JCI93940

136. Xiu Y, Dong Q, Li Q, Li F, Borcherding N, Zhang W, et al. Stabilization of NF-KB-Inducing Kinase Suppresses MLL-AF9-Induced Acute Myeloid Leukemia. Cell Rep (2018) 22(2):350-8. doi: 10.1016/j.celrep.2017.12.055

137. Kuo HP, Wang Z, Lee DF, Iwasaki M, Duque-Afonso J, Wong SH, et al. Epigenetic Roles of MLL Oncoproteins are Dependent on NF-KappaB. Cancer Cell (2013) 24(4):423-37. doi: 10.1016/j.ccr.2013.08.019

138. Jacque E, Tchenio T, Piton G, Romeo PH, Baud V. Rela Repression of RelB Activity Induces Selective Gene Activation Downstream of TNF Receptors. Proc Natl Acad Sci U S A (2005) 102(41):14635-40. doi: 10.1073/ pnas.0507342102

139. Verstovsek S, Mesa RA, Gotlib J, Levy RS, Gupta V, DiPersio JF, et al. A Double-Blind, Placebo-Controlled Trial of Ruxolitinib for Myelofibrosis. N Engl J Med (2012) 366(9):799-807. doi: 10.1056/NEJMoa1110557

140. Harrison C, Kiladjian JJ, Al-Ali HK, Gisslinger H, Waltzman R, Stalbovskaya V, et al. JAK Inhibition With Ruxolitinib Versus Best Available Therapy for Myelofibrosis. N Engl J Med (2012) 366(9):787-98. doi: 10.1056/ NEJMoa1110556

141. Pardanani A, Lasho T, Smith G, Burns CJ, Fantino E, Tefferi A. CYT387, a Selective JAK1/JAK2 Inhibitor: In Vitro Assessment of Kinase Selectivity and Preclinical Studies Using Cell Lines and Primary Cells From Polycythemia Vera Patients. Leukemia (2009) 23(8):1441-5. doi: 10.1038/leu.2009.50

142. Mascarenhas JO, Talpaz M, Gupta V, Foltz LM, Savona MR, Paquette R, et al. Primary Analysis of a Phase II Open-Label Trial of INCB039110, a Selective JAK1 Inhibitor, in Patients With Myelofibrosis. Haematologica (2017) 102(2):327-35. doi: 10.3324/haematol.2016.151126

143. Gupta V, Mesa RA, Deininger MW, Rivera CE, Sirhan S, Brachmann CB, et al. A Phase 1/2, Open-Label Study Evaluating Twice-Daily Administration of Momelotinib in Myelofibrosis. Haematologica (2017) 102(1):94-102. doi: 10.3324/haematol.2016.148924

144. Pardanani A, Gotlib JR, Jamieson C, Cortes JE, Talpaz M, Stone RM, et al. Safety and Efficacy of TG101348, a Selective JAK2 Inhibitor, in Myelofibrosis. J Clin Oncol (2011) 29(7):789-96. doi: 10.1200/JCO. 2010.32.8021

145. Pardanani A, Laborde RR, Lasho TL, Finke C, Begna K, Al-Kali A, et al. Safety and Efficacy of CYT387, a JAK1 and JAK2 Inhibitor, in Myelofibrosis. Leukemia (2013) 27(6):1322-7. doi: 10.1038/leu.2013.71

146. Morris R, Kershaw NJ, Babon JJ. The Molecular Details of Cytokine Signaling Via the JAK/STAT Pathway. Protein Sci (2018) 27(12):19842009. doi: 10.1002/pro.3519

147. Rhyasen GW, Bolanos L, Fang J, Jerez A, Wunderlich M, Rigolino C, et al. Targeting IRAK1 as a Therapeutic Approach for Myelodysplastic Syndrome. Cancer Cell (2013) 24(1):90-104. doi: 10.1016/j.ccr.2013.05.006

148. Yue L, Bartenstein M, Zhao W, Ho WT, Han Y, Murdun C, et al. Efficacy of ALK5 Inhibition in Myelofibrosis. JCI Insight (2017) 2(7):e90932. doi: $10.1172 /$ jci.insight.90932

149. Verstovsek S, Savona MR, Mesa RA, Dong H, Maltzman JD, Sharma S, et al. A Phase 2 Study of Simtuzumab in Patients With Primary, PostPolycythaemia Vera or Post-Essential Thrombocythaemia Myelofibrosis. Br J Haematol (2017) 176(6):939-49. doi: 10.1111/bjh.14501 
150. Verstovsek S, Hasserjian RP, Pozdnyakova O, Veletic I, Mesa RA, Foltz L, et al. PRM-151 in Myelofibrosis: Efficacy and Safety in an Open Label Extension Study. Blood (2018) 132(Supplement 1):686-6. doi: 10.1182/ blood-2018-99-115362

151. Balka KR, De Nardo D. Understanding Early TLR Signaling Through the Myddosome. J Leukoc Biol (2019) 105(2):339-51. doi: 10.1002/JLB.MR0318096R

152. Braun T, Carvalho G, Fabre C, Grosjean J, Fenaux P, Kroemer G. Targeting NF-kappaB in Hematologic Malignancies. Cell Death Differ (2006) 13 (5):748-58. doi: 10.1038/sj.cdd.4401874

153. Steensma DP, Mesa RA, Li CY, Gray L, Tefferi A. Etanercept, a Soluble Tumor Necrosis Factor Receptor, Palliates Constitutional Symptoms in Patients With Myelofibrosis With Myeloid Metaplasia: Results of a Pilot Study. Blood (2002) 99(6):2252-4. doi: 10.1182/blood.v99.6.2252

154. Wagner-Ballon O, Pisani DF, Gastinne T, Tulliez M, Chaligné R, Lacout C, et al. Proteasome Inhibitor Bortezomib Impairs Both Myelofibrosis and Osteosclerosis Induced by High Thrombopoietin Levels in Mice. Blood (2007) 110(1):345-53. doi: 10.1182/blood-2006-10-054502

155. Barosi G, Gattoni E, Guglielmelli P, Campanelli R, Facchetti F, Fisogni S, et al. Phase I/II Study of Single-Agent Bortezomib for the Treatment of Patients With Myelofibrosis. Clinical and Biological Effects of Proteasome Inhibition. Am J Hematol (2010) 85(8):616-9. doi: 10.1002/ajh.21754

156. Mesa RA, Verstovsek S, Rivera C, Pardanani A, Hussein K, Lasho T, et al. Bortezomib Therapy in Myelofibrosis: A Phase II Clinical Trial. Leukemia (2008) 22(8):1636-8. doi: 10.1038/leu.2008.32

157. Wolenski FS, Fisher CD, Sano T, Wyllie SD, Cicia LA, Gallacher MJ, et al. The NAE Inhibitor Pevonedistat (MLN4924) Synergizes With TNF- $\alpha$ to Activate Apoptosis. Cell Death Discov (2015) 1:15034. doi: 10.1038/ cddiscovery.2015.34

158. Swords RT, Kelly KR, Smith PG, Garnsey JJ, Mahalingam D, Medina E, et al. Inhibition of NEDD8-Activating Enzyme: A Novel Approach for the Treatment of Acute Myeloid Leukemia. Blood (2010) 115(18):3796-800. doi: 10.1182/blood-2009-11-254862

159. Zhou L, Chen S, Zhang Y, Kmieciak M, Leng Y, Li L, et al. The NAE Inhibitor Pevonedistat Interacts With the HDAC Inhibitor Belinostat to Target AML Cells by Disrupting the DDR. Blood (2016) 127(18):2219-30. doi: 10.1182/ blood-2015-06-653717

160. Milhollen MA, Traore T, Adams-Duffy J, Thomas MP, Berger AJ, Dang L, et al. MLN4924, a NEDD8-Activating Enzyme Inhibitor, is Active in Diffuse Large B-Cell Lymphoma Models: Rationale for Treatment of NF-\{kappa $\}$ BDependent Lymphoma. Blood (2010) 116(9):1515-23. doi: 10.1182/blood2010-03-272567

161. Khalife J, Radomska HS, Santhanam R, Huang X, Neviani P, Saultz J, et al. Pharmacological Targeting of miR-155 Via the NEDD8-Activating Enzyme Inhibitor MLN4924 (Pevonedistat) in FLT3-ITD Acute Myeloid Leukemia. Leukemia (2015) 29(10):1981-92. doi: 10.1038/leu.2015.106

162. Knorr KL, Schneider PA, Meng XW, Dai H, Smith BD, Hess AD, et al. MLN4924 Induces Noxa Upregulation in Acute Myelogenous Leukemia and Synergizes With Bcl-2 Inhibitors. Cell Death Differ (2015) 22(12):2133-42. doi: $10.1038 / \mathrm{cdd} .2015 .74$

163. Czuczman NM, Barth MJ, Gu J, Neppalli V, Mavis C, Frys SE, et al. Pevonedistat, a NEDD8-activating Enzyme Inhibitor, is Active in Mantle Cell Lymphoma and Enhances Rituximab Activity In Vivo. Blood (2016) 127 (9):1128-37. doi: 10.1182/blood-2015-04-640920

164. Leclerc GM, Zheng S, Leclerc GJ, DeSalvo J, Swords RT, Barredo JC. The NEDD8-Activating Enzyme Inhibitor Pevonedistat Activates the Eif2 $\alpha$ and mTOR Pathways Inducing UPR-Mediated Cell Death in Acute Lymphoblastic Leukemia. Leuk Res (2016) 50:1-10. doi: 10.1016/j.leukres.2016.09.007

165. Dai Y, Rahmani M, Dent P, Grant S. Blockade of Histone Deacetylase Inhibitor-Induced RelA/p65 Acetylation and NF-kappaB Activation Potentiates Apoptosis in Leukemia Cells Through a Process Mediated by Oxidative Damage, XIAP Downregulation, and C-Jun N-terminal Kinase 1 Activation. Mol Cell Biol (2005) 25(13):5429-44. doi: 10.1128/ MCB.25.13.5429-5444.2005

166. Ashburner BP, Westerheide SD, Baldwin AS. The p65 (RelA) Subunit of NFkappaB Interacts With the Histone Deacetylase (HDAC) Corepressors HDAC1 and HDAC2 to Negatively Regulate Gene Expression. Mol Cell Biol (2001) 21(20):7065-77. doi: 10.1128/MCB.21.20.7065-7077.2001
167. Swords RT, Erba HP, DeAngelo DJ, Bixby DL, Altman JK, Maris M, et al. Pevonedistat (MLN4924), a First-in-Class NEDD8-Activating Enzyme Inhibitor, in Patients With Acute Myeloid Leukaemia and Myelodysplastic Syndromes: A Phase 1 Study. Br J Haematol (2015) 169(4):534-43. doi: 10.1111/bjh.13323

168. Swords RT, Watts J, Erba HP, Altman JK, Maris M, Anwer F, et al. Expanded Safety Analysis of Pevonedistat, a First-in-Class NEDD8-Activating Enzyme Inhibitor, in Patients With Acute Myeloid Leukemia and Myelodysplastic Syndromes. Blood Cancer J (2017) 7(2):e520. doi: 10.1038/bcj.2017.1

169. Swords RT, Coutre S, Maris MB, Zeidner JF, Foran JM, Cruz J, et al. Pevonedistat, a First-in-Class NEDD8-activating Enzyme Inhibitor, Combined With Azacitidine in Patients With AML. Blood (2018) 131 (13):1415-24. doi: 10.1182/blood-2017-09-805895

170. Liu X, Jiang Y, Wu J, Zhang W, Liang Y, Jia L, et al. NEDD8-Activating Enzyme Inhibitor, MLN4924 (Pevonedistat) Induces NOXA-Dependent Apoptosis Through Up-Regulation of ATF-4. Biochem Biophys Res Commun (2017) 488(1):1-5. doi: 10.1016/j.bbrc.2017.04.122

171. Milhollen MA, Narayanan U, Soucy TA, Veiby PO, Smith PG, Amidon B. Inhibition of NEDD8-Activating Enzyme Induces Rereplication and Apoptosis in Human Tumor Cells Consistent With Deregulating CDT1 Turnover. Cancer Res (2011) 71(8):3042-51. doi: 10.1158/0008-5472.CAN$10-2122$

172. Blank JL, Liu XJ, Cosmopoulos K, Bouck DC, Garcia K, Bernard H, et al. Novel DNA Damage Checkpoints Mediating Cell Death Induced by the NEDD8-Activating Enzyme Inhibitor MLN4924. Cancer Res (2013) 73 (1):225-34. doi: 10.1158/0008-5472.CAN-12-1729

173. Lin JJ, Milhollen MA, Smith PG, Narayanan U, Dutta A. NEDD8-Targeting Drug MLN4924 Elicits DNA Rereplication by Stabilizing Cdt1 in S Phase, Triggering Checkpoint Activation, Apoptosis, and Senescence in Cancer Cells. Cancer Res (2010) 70(24):10310-20. doi: 10.1158/0008-5472.CAN-102062

174. Boddu P, Carter BZ, Verstovsek S, Pemmaraju N. SMAC Mimetics as Potential Cancer Therapeutics in Myeloid Malignancies. Br J Haemato (2019) 185(2):219-31. doi: 10.1111/bjh.15829

175. Gaither A, Porter D, Yao Y, Borawski J, Yang G, Donovan J, et al. A Smac Mimetic Rescue Screen Reveals Roles for Inhibitor of Apoptosis Proteins in Tumor Necrosis Factor-Alpha Signaling. Cancer Res (2007) 67(24):11493-8. doi: 10.1158/0008-5472.CAN-07-5173

176. Petersen SL, Wang L, Yalcin-Chin A, Li L, Peyton M, Minna J, et al. Autocrine TNFalpha Signaling Renders Human Cancer Cells Susceptible to Smac-Mimetic-Induced Apoptosis. Cancer Cell (2007) 12(5):445-56. doi: 10.1016/j.ccr.2007.08.029

177. Varfolomeev E, Blankenship JW, Wayson SM, Fedorova AV, Kayagaki N, Garg P, et al. IAP Antagonists Induce Autoubiquitination of c-IAPs, NFkappaB Activation, and TNFalpha-Dependent Apoptosis. Cell (2007) 131 (4):669-81. doi: 10.1016/j.cell.2007.10.030

178. Vince JE, Wong WW, Khan N, Feltham R, Chau D, Ahmed AU, et al. IAP Antagonists Target cIAP1 to Induce TNFalpha-Dependent Apoptosis. Cell (2007) 131(4):682-93. doi: 10.1016/j.cell.2007.10.037

179. Wu H, Tschopp J, Lin SC. Smac Mimetics and TNFalpha: A Dangerous Liaison? Cell (2007) 131(4):655-8. doi: 10.1016/j.cell.2007.10.042

180. Craver BM, Nguyen TK, Nguyen J, Nguyen H, Huynh C, Morse SJ, et al. The SMAC Mimetic LCL-161 Selectively Targets JAK2. Exp Hematol Oncol (2020) 9:1. doi: 10.1186/s40164-019-0157-6

181. Pemmaraju N, Carter BZ, Kantarjian HM, Cortes JE, Bose P, Kadia TM, et al. Final Results of Phase 2 Clinical Trial of LCL161, a Novel Oral SMAC Mimetic/Iap Antagonist, for Patients With Intermediate to High Risk Myelofibrosis. Blood (2019) 134(Supplement_1):555-5. doi: 10.1182/blood2019-130046

182. Quotti Tubi L, Canovas Nunes S, Brancalion A, Doriguzzi Breatta E, Manni S, Mandato E, et al. Protein Kinase CK2 Regulates AKT, NF- אB and STAT3 Activation, Stem Cell Viability and Proliferation in Acute Myeloid Leukemia. Leukemia (2017) 31(2):292-300. doi: 10.1038/leu.2016.209

183. Laouedj M, Tardif MR, Gil L, Raquil MA, Lachhab A, Pelletier M, et al. S100A9 Induces Differentiation of Acute Myeloid Leukemia Cells Through TLR4. Blood (2017) 129(14):1980-90. doi: 10.1182/blood-2016-09-738005

184. Abdul-Aziz AM, Shafat MS, Mehta TK, Di Palma F, Lawes MJ, Rushworth SA, et al. MIF-Induced Stromal PKC $/$ /LL8 Is Essential in Human Acute 
Myeloid Leukemia. Cancer Res (2017) 77(2):303-11. doi: 10.1158/00085472.CAN-16-1095

185. Cervantes F, Pereira A. Does Ruxolitinib Prolong the Survival of Patients With Myelofibrosis? Blood (2017) 129(7):832-7. doi: 10.1182/blood-201611-731604

186. Verstovsek S, Mesa RA, Gotlib J, Gupta V, DiPersio JF, Catalano JV, et al. Long-Term Treatment With Ruxolitinib for Patients With Myelofibrosis: 5Year Update From the Randomized, Double-Blind, Placebo-Controlled, Phase 3 COMFORT-I Trial. J Hematol Oncol (2017) 10(1):55. doi: 10.1186/s13045-017-0417-z

187. Kiladjian JJ, Cassinat B, Chevret S, Turlure P, Cambier N, Roussel M, et al. Pegylated Interferon-Alfa-2a Induces Complete Hematologic and Molecular Responses With Low Toxicity in Polycythemia Vera. Blood (2008) 112 (8):3065-72. doi: 10.1182/blood-2008-03-143537

188. Essers MA, Offner S, Blanco-Bose WE, Waibler Z, Kalinke U, Duchosal MA, et al. IFNalpha Activates Dormant Haematopoietic Stem Cells In Vivo. Nature (2009) 458(7240):904-8. doi: 10.1038/nature07815

189. Quintas-Cardama A, Kantarjian H, Manshouri T, Luthra R, Estrov Z, Pierce $\mathrm{S}$, et al. Pegylated Interferon Alfa-2a Yields High Rates of Hematologic and Molecular Response in Patients With Advanced Essential Thrombocythemia and Polycythemia Vera. J Clin Oncol (2009) 27(32):5418-24. doi: 10.1200/ jco.2009.23.6075

190. Verger E, Cassinat B, Chauveau A, Dosquet C, Giraudier S, Schlageter MH, et al. Clinical and Molecular Response to Interferon-Alpha Therapy in
Essential Thrombocythemia Patients With CALR Mutations. Blood (2015) 126(24):2585-91. doi: 10.1182/blood-2015-07-659060

191. Kiladjian JJ, Giraudier S, Cassinat B. Interferon-Alpha for the Therapy of Myeloproliferative Neoplasms: Targeting the Malignant Clone. Leukemia (2016) 30(4):776-81. doi: 10.1038/leu.2015.326

192. Hasselbalch HC, Holmstrom MO. Perspectives on Interferon-Alpha in the Treatment of Polycythemia Vera and Related Myeloproliferative Neoplasms: Minimal Residual Disease and Cure? Semin Immunopathol (2019) 41(1):519. doi: $10.1007 / \mathrm{s} 00281-018-0700-2$

193. Mondello P, Di Mirto C, Cuzzocrea S, Arrigo C, Mian M, Pitini V. Interferon Alpha has a Strong Anti-Tumor Effect in Philadelphia-Negative Myeloproliferative Neoplasms. Clin Lymphoma Myeloma Leuk (2019) 19 (8):e489-95. doi: 10.1016/j.clml.2019.03.027

Conflict of Interest: The authors declare that the research was conducted in the absence of any commercial or financial relationships that could be construed as a potential conflict of interest.

Copyright (c) 2021 Fisher, Fowles, Zhou and Oh. This is an open-access article distributed under the terms of the Creative Commons Attribution License (CC BY). The use, distribution or reproduction in other forums is permitted, provided the original author(s) and the copyright owner(s) are credited and that the original publication in this journal is cited, in accordance with accepted academic practice. No use, distribution or reproduction is permitted which does not comply with these terms. 